\title{
Modelling Residual Stress and Phase Transformations in Steel Welds
}

\author{
Hui Dai \\ School of Materials, University of Manchester, Manchester \\ UK
}

\section{Introduction}

Mathematical modelling of welding phenomena is very complex: involving melt pool phenomena, solidification, weldability analysis, microstructure evolution in the heat affected zone, welding heat-flow simulation, electrical-thermal-mechanical simulation etc. Some interactions between these processes are included in Fig. 1. Each topic alone can be intellectually challenging and too hard to be investigated by classical methods. With the increasing power of modern computer systems, numerical modelling and especially finite element analyses make it possible to produce excellent solutions to satisfy engineering demands.

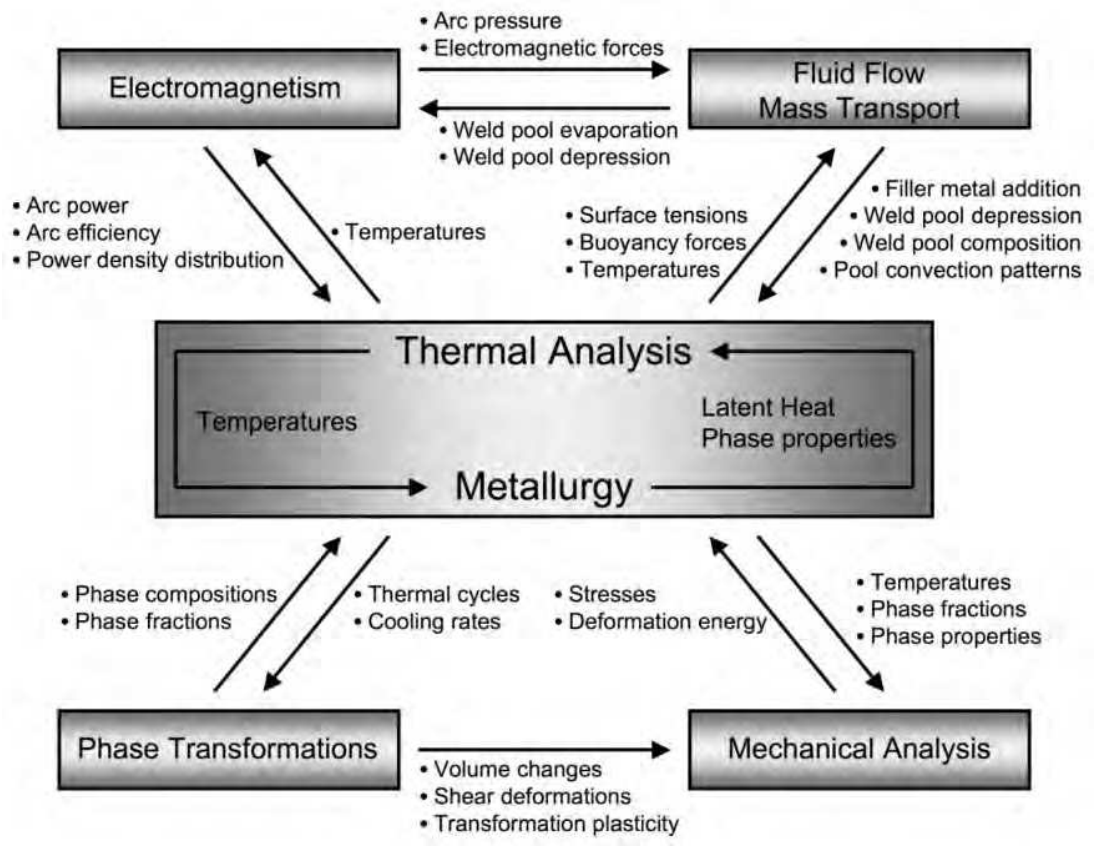

Fig. 1. Interrelated physical phenomena that arise in arc welding of ferritic steels $[1,2]$ 
Finite element analysis offers a powerful technique for elaborating on the factors that affect the formation and distribution of residual stresses in engineering components. For the useful application of this technique for welds in pressure vessel components it is necessary that developments be made to allow analyses of large complex structures and with the successful management of metallurgical effects (e.g. phase transformations and microstructural evolution).

\section{Finite element analysis of welding}

This section is concerned with simulations of temperatures, displacements, stresses and strains in welded structure [3] without solid-state phase transformations. Detailed literature review in finite element analysis of welding (2001 and before) can be found in a paper by Lindgren [4].

\subsection{Heat conducting equations}

Consider a particle with a differential volume $d \Omega$ at the position $x$ at time $t$. Let $u$ denote its internal energy, $K E$ the kinetic energy, $Q_{c}$, the net rate of heat flow by conduction into the particle from its surroundings, $Q_{s}$, the rate of heat input due to external sources (such as radiation) and $P$ the rate at which work is done on the particle by body forces and surface forces (i.e., $P$ is the mechanical power input). Then, in the absence of other forms of energy input, the fundamental postulate of conservation of energy states that [5]

$$
\frac{d}{d t}(U+K E)=P+Q_{c}+Q_{s}
$$

And as shown by Lai [5], the energy equation at each point of the continuum reduces to

$$
\rho \frac{d u}{d t}=\operatorname{tr}(\mathbf{T D})-\operatorname{div} \mathbf{q}+\rho \mathbf{q}_{\mathbf{s}}
$$

where $\mathbf{q}_{\mathrm{s}}$ is the rate of heat input (known simply as the heat supply or heat flux vector) per unit mass by external sources, $\mathbf{q}$ is a vector whose magnitude gives the rate of heat flow across a unit area by conduction and whose direction gives the direction of heat flow, then by Fourier's law, $\mathbf{q}=-k \cdot \operatorname{grad} T, k(\mathrm{~T})$ is the thermal conductivity, $\mathrm{T}$ is the temperature. The term $\operatorname{tr}(\mathbf{T D})=P_{s}$ is known as the stress power (per unit volume). It represents the rate at which work is done to change the volume and shape of a particle of unit volume. Finally, $T$ is the Cauchy stress and $\mathbf{D}$ is the tensor describing the rate of deformation.

Equation (2) represents the energy equation for two-way coupling. The stress power $P_{s}$ couples the mechanical state to the thermal state; i.e., mechanical work causes heating.

In one way coupling, the stress power term is assumed negligible compared to the heat input terms on the right-hand side of equation (2), and it is also assumed that the internal energy is only a function of the temperature, i.e., independent of strains. Thus, equation (2) becomes:

$$
\rho \frac{d u}{d t}=-\operatorname{div} \mathbf{q}+\rho \mathbf{q}_{\mathbf{s}}
$$


Now using Fourier's law $\mathbf{q}=-k \cdot \operatorname{grad} T$, we have

$$
\rho \frac{d u}{d t}=\operatorname{div}(k \cdot \operatorname{grad} T)+\rho \mathbf{q}_{\mathbf{s}}
$$

where $\rho(T)$ is the density, and $T$ is the temperature. Introducing the specific heat, $C$, of the medium define by

$$
C=\frac{d u}{d t}
$$

We can write equation (4) as

$$
\rho C \frac{\partial T}{\partial t}=\operatorname{div}(k \cdot \operatorname{grad} T)+\rho \mathbf{q}_{\mathbf{s}}
$$

$\frac{\partial T}{\partial t}$ is the change in temperature over time, $k(\mathrm{~T})$ is the thermal conductivity, the product $\rho C$ reflects the capacity of the material to store energy.

For a constant pressure process the change of specific enthalpy is equal to the heat transfer, i.e., specific heat, $C_{p}=\frac{d H}{d T}$, where $\mathrm{H}$ is the specific enthalpy, the subscript ' $\mathrm{p}$ ' refers to constant pressure. The equation (4) now becomes

$$
\rho \frac{d H}{d t}=\operatorname{div}(k \cdot \operatorname{grad} T)+\rho \mathbf{q}_{\mathbf{s}}
$$

$H$ is a function of temperature.

In gas tungsten arc (GTAW or TIG) welding, the area-specific density of heat flow to the weld pool by the welding arc over a small area of the work-piece is of the order of $5 \times 10^{0}$ to $5 \times 10^{2} \mathrm{~W} / \mathrm{mm}^{2}[6]$. As a result of this intense local heat flux, there are high temperature gradients in the neighbourhood of the weld pool. It is therefore assumed that the stress power term is small compared to the heat input terms of the energy equation, and that modelling the welding process as one-way coupling, neglecting coupling between mechanical and thermal problems, is reasonable.

\subsection{Thermal boundary and initial conditions}

Initial and boundary conditions need to be specified to solve equation (7). Various types of conditions are necessary to transform the real physical conditions into mathematical models [5]. Consider an arbitrary fixed volume, $\Omega$, of the medium which is bounded by a closed surface $S$.

a. Temperature conditions

Initial conditions are required only when dealing with transient heat transfer problems in which the temperature field in the material changes with time. 


$$
T=T(\mathbf{X}, 0), \mathbf{X} \in \Omega
$$

Specified boundary conditions are required in the analysis of all transient or steady-state problems.

$$
T=T(\mathbf{X}, t), \mathbf{X} \in S
$$

b. Surface heat flux

$$
\mathbf{q}=\mathbf{q}(\mathbf{X}, t), \mathbf{X} \in S
$$

c. Volumetric heat flux

$$
T=\mathbf{r}(\mathbf{X}, t), \mathbf{X} \in \Omega
$$

d. Convection

$$
\mathbf{q}=h\left(T-T^{0}\right), \mathbf{X} \in S
$$

where $h=h(\mathbf{X}, t)$ is the film coefficient and $T^{0}=T^{0}(\mathbf{X}, t)$ is the sink temperature.

e. Radiation

$$
\mathbf{q}=A\left(\left(T-T^{z}\right)^{4}-\left(T^{0}-T^{z}\right)^{4}\right), \mathbf{X} \in S
$$

where $A$ is the radiation constant (emissivity multiplied by the Stefan-Boltzmann constant) and $T^{Z}$ is the temperature corresponding to absolute zero on the scale used. For example $T^{Z}$ $=-273^{\circ} \mathrm{C}$ or $0 \mathrm{k}$.

\subsection{Moving heat sources}

Chemical processes occurring in the weld pool, at elevated temperatures, and the choice of welding consumables affect the weld metal composition [6]. During the heating stage, heat energy has to be supplied to the solidus area. This solidus area includes weld nugget and a portion of the work pieces (weld pool). If the size and shape of a solidus area of the moving molten pool (equivalent heat source) is not determined, then an analytically specified volumetric heat source is used. The parameters of the heat sources are adjusted in a way that the result is approximately the shape of the molten zone. For each welding process a specific type of heat source is most effective. In MIG, TIG, welding residual stresses analysis, most researchers use a simplified 3D double ellipsoid model (see Fig. 2) developed by Goldak [7] for modelling of the heat source $[8,9]$. It should be noted that the double ellipsoid heat source uses a Gaussian distribution of heat input. Whatever heat source is used, the mesh must be fine enough to capture the total amount of heat deposited.

In the Goldak model, the fractions of heat deposited in the front and rear of heat source are denoted by $f_{f}$ and $f_{r}$, respectively, and these fractions are specified to satisfy $f_{f}+f_{r}=2$. Let $q$ denote the power density in $\mathrm{W} / \mathrm{m}^{3}$ within the ellipsoid, and let $a, b$, and $c$ denote the semiaxes of the ellipsoid parallel to the $x, y, z$ axes. Then the power distribution inside the front and rear quadrant can be specified by 


$$
q(x, y, z, t)=\frac{6 \cdot \sqrt{3} \cdot f_{f, r} \cdot Q}{a \cdot b \cdot c_{1,2} \cdot \pi \cdot \sqrt{\pi}} \exp \frac{\frac{-3 \cdot x^{2}}{a^{2}}}{\exp }{ }^{\frac{-3 \cdot y^{2}}{b^{2}}} \exp \frac{\frac{-3(z-v \cdot(\tau-t))^{2}}{c_{1,2}^{2}}}{}
$$

In equation (14), $Q$ is the heat available at the source, $v$ is welding speed, $\tau$ is a lag time necessary to define the position of the heat source at time $t=0$. For an electric arc the heat available is

$$
\mathrm{Q}=\mathrm{\eta VI}
$$

Where $\eta$ is the heat source efficiency, $0 \leq \eta \leq 1, V$ is the arc voltage, and $I$ is the arc current. The parameters $a, b, c_{1}$, and $c_{2}$ are independent, and can take on different values for the front and rear quadrants of the source to properly represent the weld arc.

In the case the moving heat load is applied on the top surface of the model, some researchers [10,11] employed a modified Gaussian distribution model of the arc heat flux. This states that [11]:

$$
q(x, z, t)=\frac{3 Q_{f, r}}{\pi a c_{1,2}} \exp \frac{\frac{-3 x^{2}}{a^{2}}}{\exp } \frac{-3(z-v(\tau-t))^{2}}{c_{1,2}^{2}}
$$

It should be noted that in the case of the modelling of high energy welding process like laser, electron beam, a conical heat source would be more satisfactory [12].

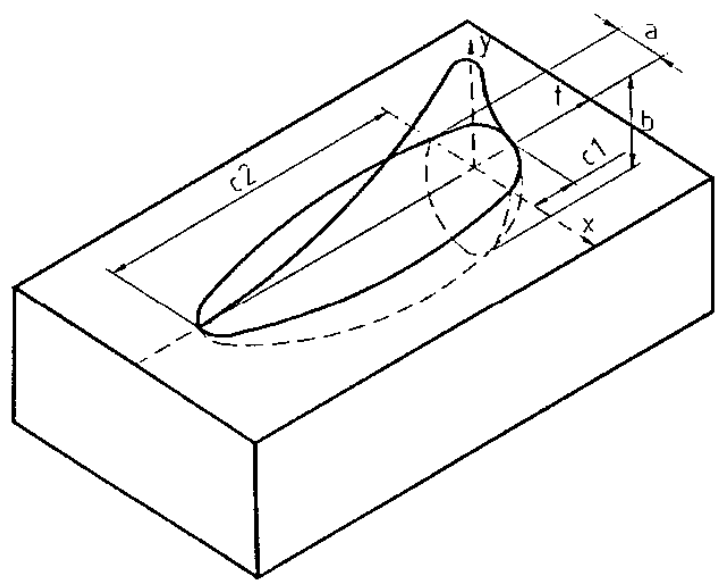

Fig. 2. Goldak double ellipsoid heat source model [6].

\subsection{Latent heat effect}

Latent heat has to be taken into consideration in case of microstructure transformations and melting solidification. Latent heat influences the formation of the transient temperature field. The metallurgical transformations depend on the thermal history. The thermal properties can be derived from the proportions of phase using mixture rule. 


$$
k\left(p_{i}, T\right)=\sum_{\text {phases }} p_{i} k_{i}(T) \rho\left(\rho_{i}, T\right)=\sum_{\text {phases }} p_{i} \rho_{i}(T) H\left(H_{i}, T\right)=\sum_{\text {phases }} p_{i} H_{i}(T)
$$

For a two-phase transformation, we have $H\left(p_{1}, p_{2}, T\right)=p_{1} H_{1}(T)+p_{2} H_{2}(T)$ and $p_{1}+p_{2}=1$. Substituting them into equation (7), it gives:

$$
\rho\left(p_{1} \frac{d H_{1}}{d T}+p_{2} \frac{d H_{2}}{d T}\right) \dot{T}=\operatorname{div}(k \cdot \operatorname{grad} T)+\rho \mathbf{q}_{\mathbf{s}}-\rho \dot{p}_{2}\left(H_{2}-H_{1}\right)
$$

where $\left(p_{1} \frac{d H_{1}}{d T}+p_{2} \frac{d H_{2}}{d T}\right)$ represent an equivalent specific heat and $\rho \dot{p}_{2}\left(H_{2}-H_{1}\right)$ is latent heat of transformation.

The finite element method for thermal computation involves the solution of the system of differential equations as follow [28]:

$$
\mathbf{C} \cdot \mathbf{T}+\mathbf{K} \cdot \mathbf{T}=\mathbf{Q}
$$

where $\mathbf{T}$ is a vector of nodal temperature, $\mathbf{C}$ is the specific heat matrix, $\mathbf{K}$ is the conductivity matrix and $\mathbf{Q}$ is the vector of nodal powers equivalent to internal heat sources and boundary conditions.

\subsection{Mechanical analysis}

One important aspect in weld modelling is melting/re-melting effect. The strains in a weld are annealed at high temperatures. To understand material behaviour at elevated temperature, Dong et al [13] examined a simple one dimension (1D) thermo-plasticity problem. It shows that continuum and structural mechanics based FE codes are not intended to deal with material state (e.g., from solid to liquid) change. As a result, the standard FE computation results in accumulated plastic strains and gives wrong solutions. Therefore, a material point going through melting or re-melting should lose memory (prior plastic strain annihilation) on cooling. It was stated that [13], among all phase change effects, melting/re-melting effects are the most important in residual stress analysis.

As the weld torch moves, weld material is laid down below and behind the torch. Material deposition is another important aspect of finite element modelling of the weld process. Typically the finite element model of the weld joint contains the parent metal plate and all the weld passes in a single mesh. Welding of each pass is simulated in separate steps or subanalyses. To simulate the first pass of a multi-pass weld the future weld passes are removed using a feature available within the finite element code. Feng et al. [14] use a special user material property subroutine within ABAQUS [15] where elements representing the weld metal are assigned the thermal properties of air during the thermal analysis. The weld bead elements always exist during the thermal analysis, but the thermal conductivity and the heat capacity of these elements are assigned small values to represent air, but then switched to the actual metal properties when the element enters the moving weld pool. For the mechanical analysis, a similar approach is used where the elements to be welded are first assigned a set of artificial, very soft properties. As the elements solidify from the weld pool the actual properties of the metal are reassigned. 
SYSWELD [16], a specific welding simulation code use a special process called the chewing gum method'. The filler material is declared as an artificial phase which differs from hot but not yet molten material in the property; the modulus of elasticity is a fixed low value, for example $1.0 \mathrm{~N} / \mathrm{mm}^{2}$ for solids and $5.0 \mathrm{~N} / \mathrm{mm}^{2}$ for shells; the thermal strains are zero; this material - called 'chewing gum' - does not disturb the overall answer of the structure, and it behaves in a purely elastic manner; above the melting temperature, the chewing gum phase transfers to molten material within a small temperature range.

\subsection{Case study: bead on plate analysis}

This section describes the finite element analyses of an austenitic single bead on plate (BoP) specimen, the geometry and other properties are the same as a paper presented by Dennis et al [17]. A 3D half model, invoking symmetry along the centre of the weld bead is constructed. The ABAQUS finite element mesh consists of 45024 8-node brick elements and 55013 nodes. Based on this mesh, two analyses have been carried out:

Analysis A: Surface flux moving heat source; isotropic hardening assumed; torch moving along the centre line of the weld.

Analysis B: Volumetric flux moving heat source; both mixed isotropic/kinematic hardening and kinematic hardening are investigated; "dynamic fusion boundary method" [17] is adopted and a specific torch path has been derived via trial and error in order to match the observed fusion boundary.

PATRAN and ABAQUS/CAE are used to generate the numerical model; ABAQUS/Standard is used to simulate the welding process. There are two major features in welding simulation with ABAQUS: combined thermal-mechanical analysis procedures in sequentially coupled form; definition of moving torch and weld material deposition via user subroutines ( ${ }^{*}$ DFLUX, *GAPCON, *FILM)[15].

A typical sequentially coupled thermal-stress analysis consists of two ABAQUS/Standard runs: a heat transfer analysis and a subsequent stress analysis. To capture the weld deposition, one can use the element birth [14] technique; another approach is to use the GAPCON user subroutine. In the thermal analysis, a thermal contact between the weld and the base plate will be established. The GAPCON subroutine will switch the energy transport across the contact pair from zero to a value representative of welding conditions. The GAPCON subroutine can be written to activate the conductivity across the contact pair. By controlling the torch energy input into the joint using the DFLUX user subroutine, the moving torch can be simulated. The GAPCON subroutine can be used to model continuous deposition along the bead.

The UFILM subroutine should also be considered, the subroutine captures variable convection coefficients. For welding, this subroutine is used to describe the variable convection as the weld metal is laid on the parent material, and to activate convection on the top surface of the weld material as it is deposited.

Once the thermal analysis complete, the structural analysis can be executed. The structural analysis uses the thermal analysis (temperature) results as the loading. Boundary conditions are applied to restrain the system against rigid body motion. The thermal contact between the weld material and base plates is converted to 'tied constraints'. As the weld material 
cools and becomes stiffer based on temperature dependent material properties, the tied constraint will capture the proper constraint between the weld material and the parent material plate.

In the thermal analysis, it's clear that the penetration at start is much deeper than the rest of the plate, to generate enough penetration, a smaller moving Gaussian ellipse used at start, 1.0 second start dwell assumed in analysis A. It should be noted that the same heat input was applied, regardless of the Gaussian ellipse shape \& size used. Figures 3 and 4 provided temperature contour plots showing the $1400^{\circ} \mathrm{C}$ isotherm along a longitudinal section through the middle of the bead, and a transverse section at weld mid-length, respectively. Figures 5 and 6 show $800^{\circ} \mathrm{C}$ peak temperature isotherms along the longitudinal section of the plate through the middle of the bead, and a transverse section at weld mid-length, respectively. Figure 7 shows a contour plot of von Mises stresses within the plate.

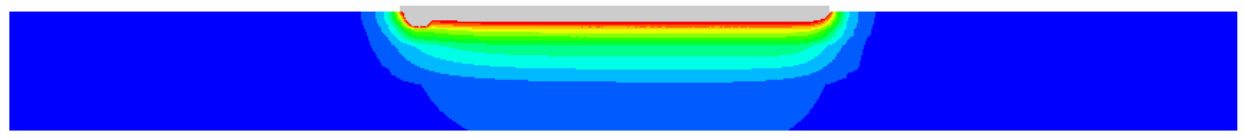

Fig. 3. $1400^{\circ} \mathrm{C}$ peak temperature profile along the centre surface (Analysis A).
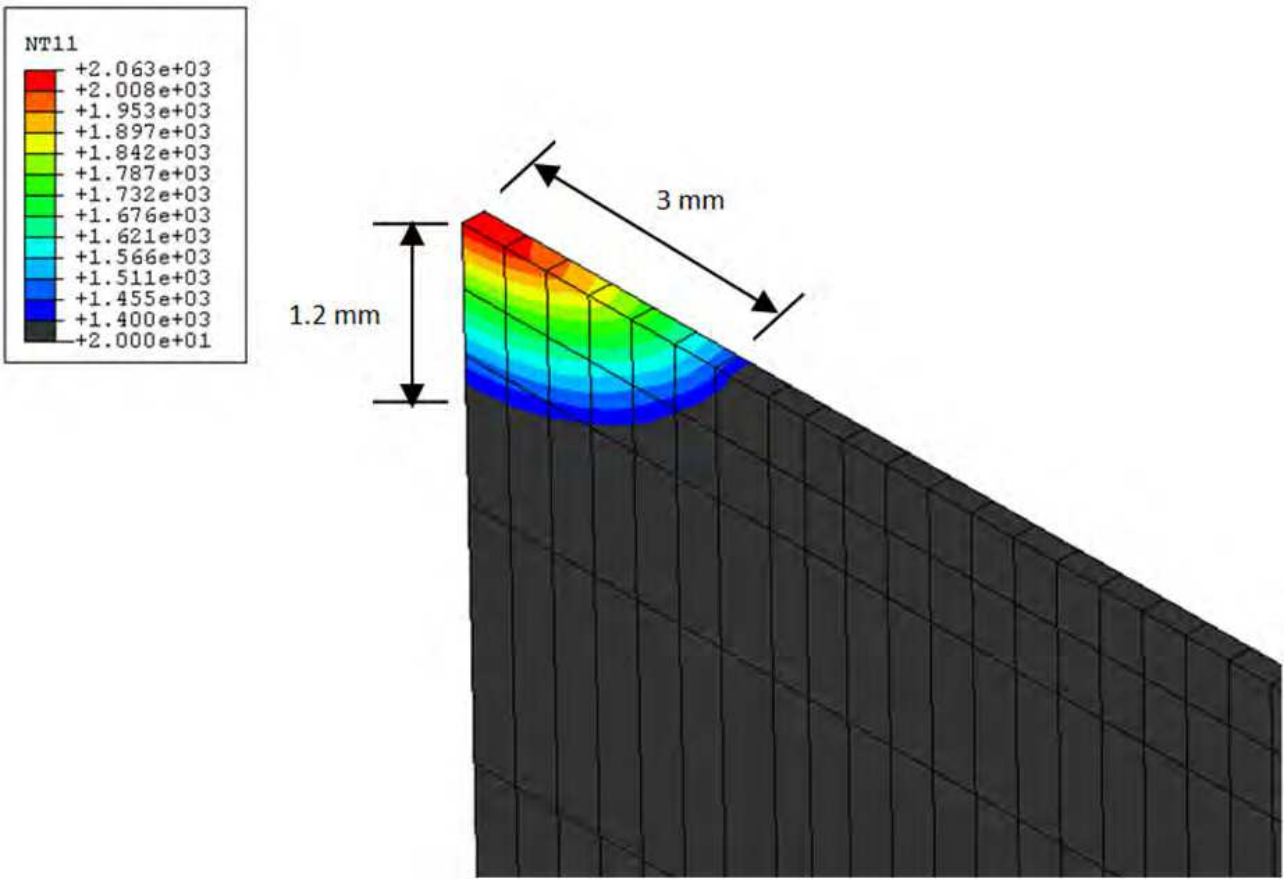

Fig. 4. Weld fusion boundary at weld mid-length (Analysis A). 


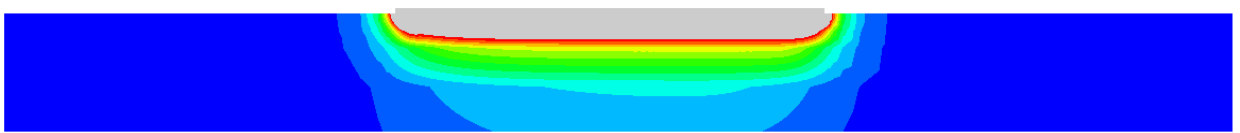

Fig. $5.800^{\circ} \mathrm{C}$ peak temperature isotherms along the centre surface (Analysis A)

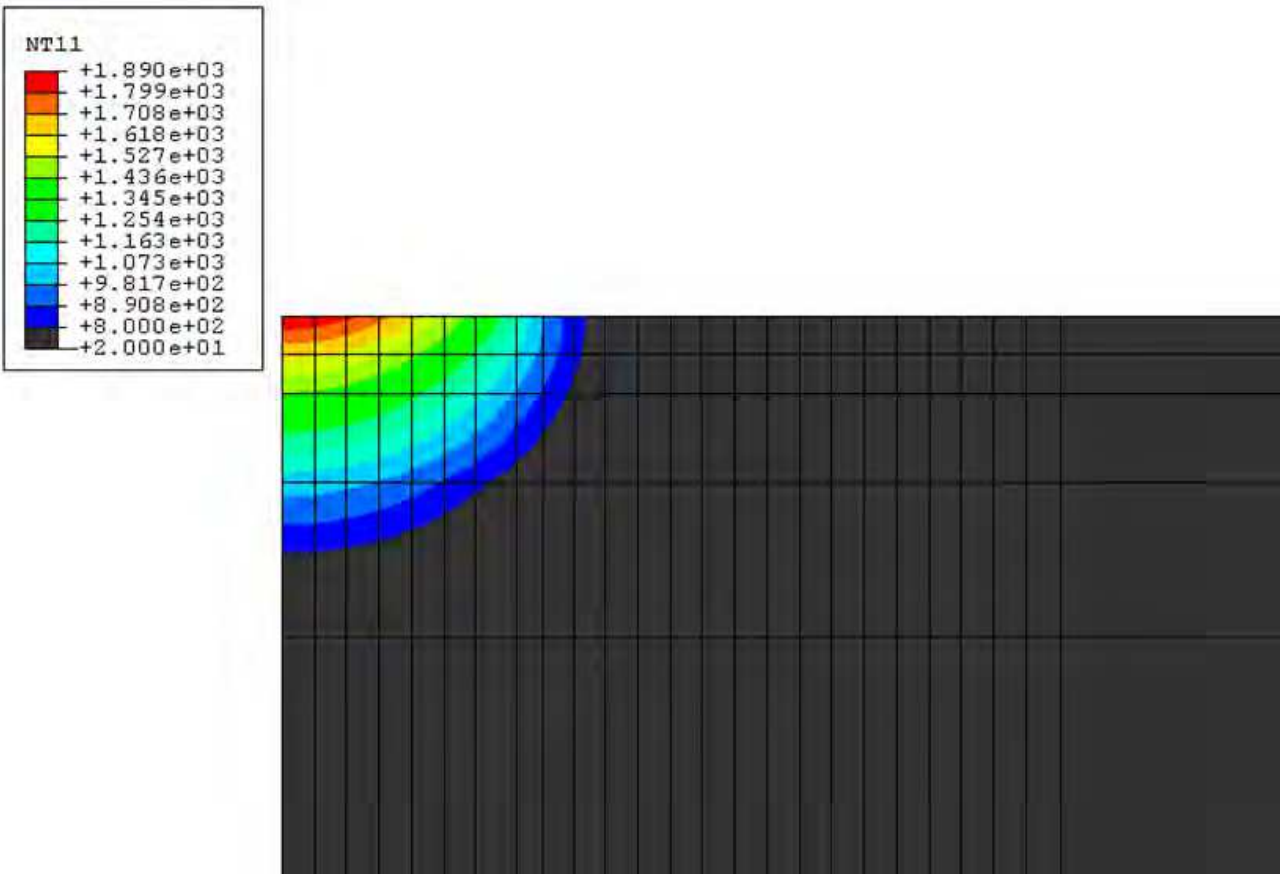

Fig. $6.800^{\circ} \mathrm{C}$ peak temperature isotherms at weld mid-length (Analysis A).

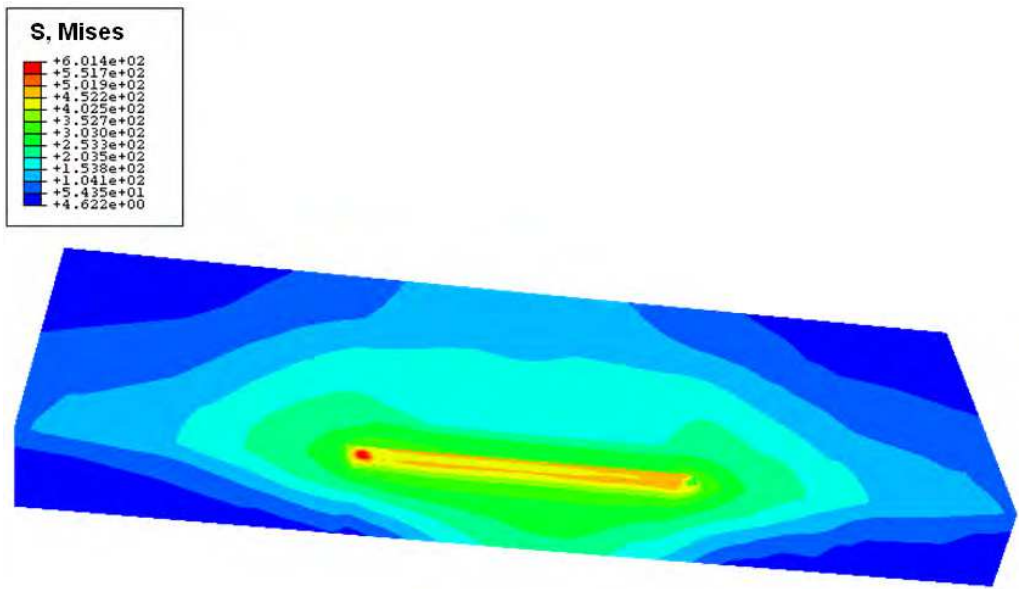

Fig. 7. Residual von Mises stress (MPa); isotropic hardening (Analysis A). 
In analysis B, because a half model is used, the power density used in equation (14) is multiplied by a coefficient $\mathrm{Kq}$ so that only half of the total heat flux deposited on the modelled plate upon integration equals the effective power from the torch, i.e.

$$
q(x, y, z, t)=k_{q} \frac{6 \cdot \sqrt{3} \cdot f_{f, r} \cdot Q}{a \cdot b \cdot c_{1,2} \cdot \pi \cdot \sqrt{\pi}} \cdot e^{\frac{-3 \cdot x^{2}}{a^{2}}} \cdot e^{\frac{-3 \cdot y^{2}}{b^{2}}} \cdot e^{\frac{-3(z-v \cdot(\tau-t))^{2}}{c_{1,2}^{2}}}
$$

Figure 8 presents fusion boundary as a longitudinal section along the middle of the bead, showing both start and stop ends of the bead.

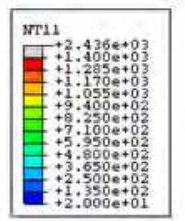

\section{Welding direction}

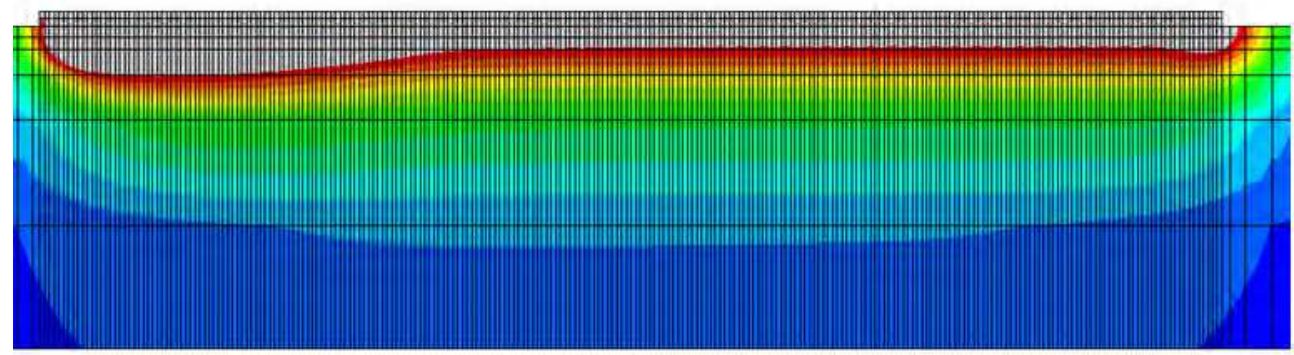

Fig. $8.1400^{\circ} \mathrm{C}$ peak temperature profile along the centre surface; torch moved along a specific path, 1.0s start dwell (Analysis B).

While Fig. 9 presents fusion boundary as 5 transverse sections, which shows 'double-lobed' effect at some sections. Figures $10-14$ show the predicted $1400^{\circ} \mathrm{C}$ isotherms compared with the macrographs in 5 transverse sections, respectively. Figure 15 shows the thermocouple measurements of the plate. Figure 16 shows the predicted transient temperature profiles.

The previous part detailed the thermal results from the bead on plate thermal analyses. This part presents the as-welded residual stress results from the subsequent mechanical analyses. Contour plots of the as-welded residual stresses results are similar between the kinematic and mixed hardening model and so contour plots are only presented for the latter in Figs. 17 and 18. These figures present longitudinal and transverse stresses on the bead symmetry plane.

A detailed comparison of the residual stresses has been performed by examination of line plot stresses along a number of sections. Here results are presented for a section on the symmetry plane, parallel to the bead but $2 \mathrm{~mm}$ below the top surface of the plate. Results are shown in Fig. 19 for longitudinal stresses and Fig. 20 for transverse stresses. 


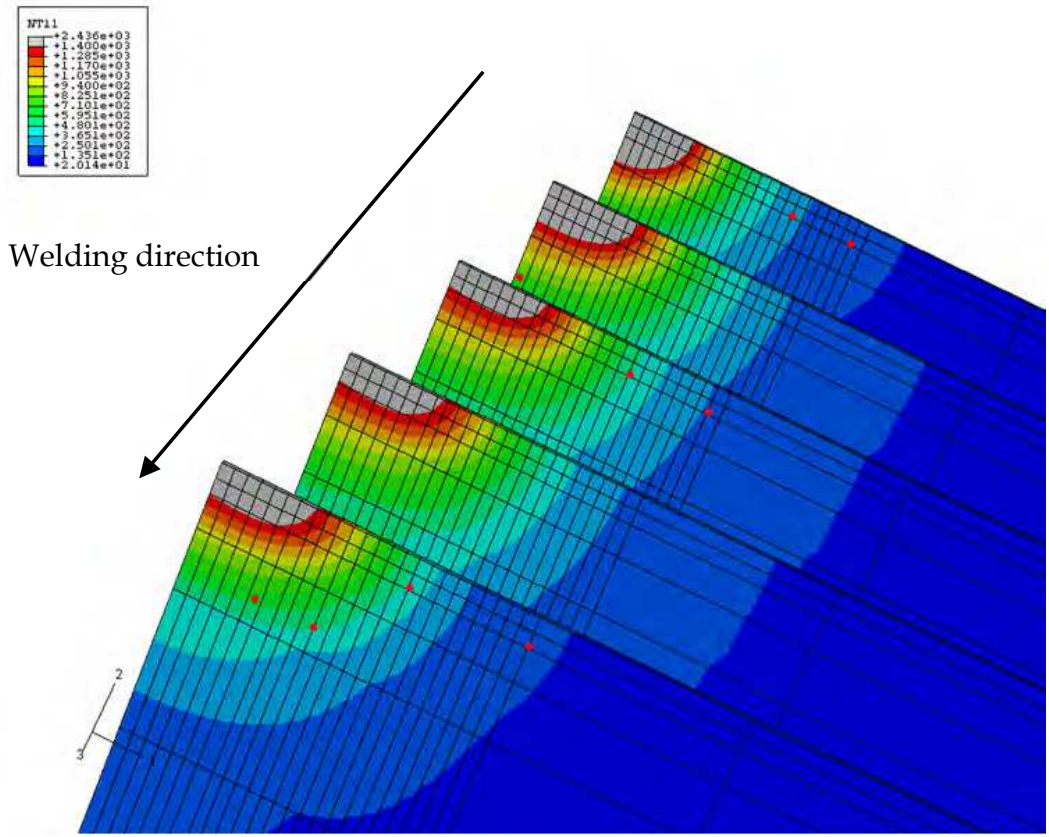

Fig. 9. Fusion boundary at different sections, thermal couples are highlighted (Analysis B).

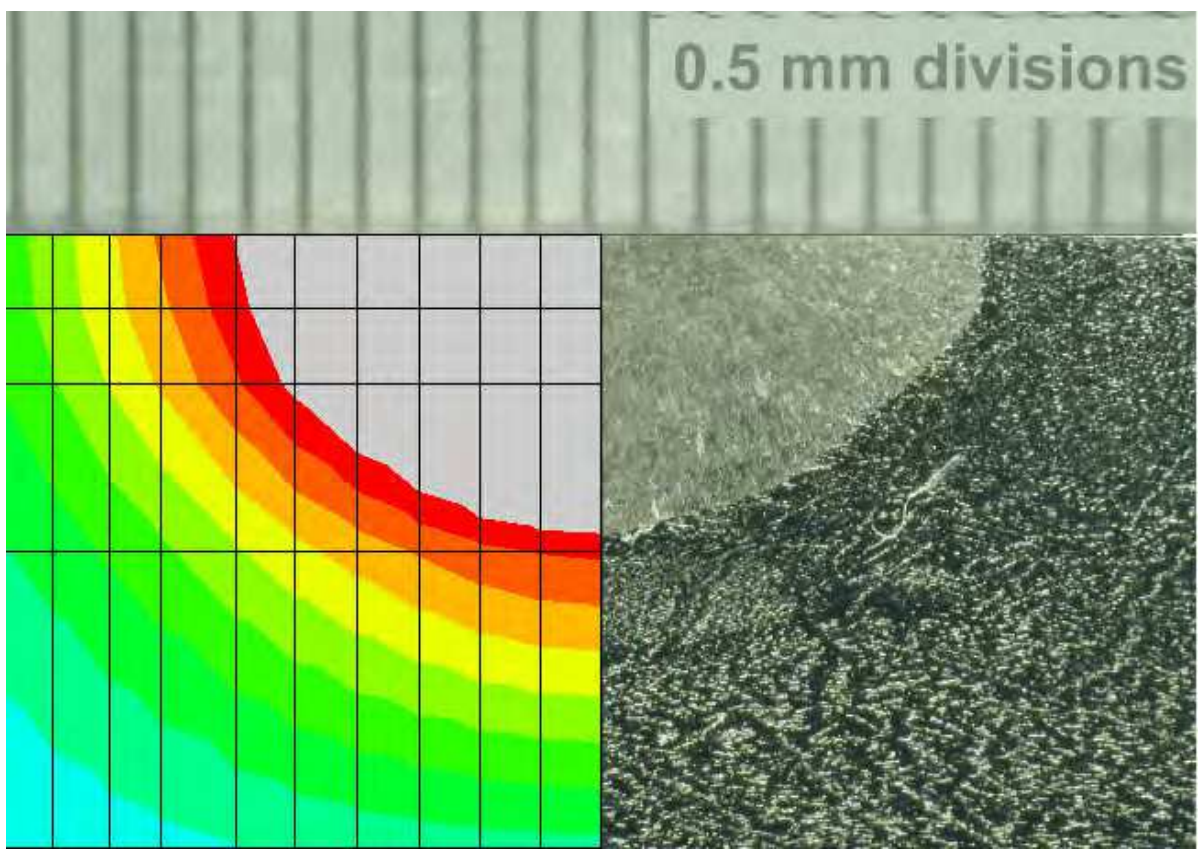

Fig. 10. Transverse section 1 (start-end) through weld bead (Analysis B). 


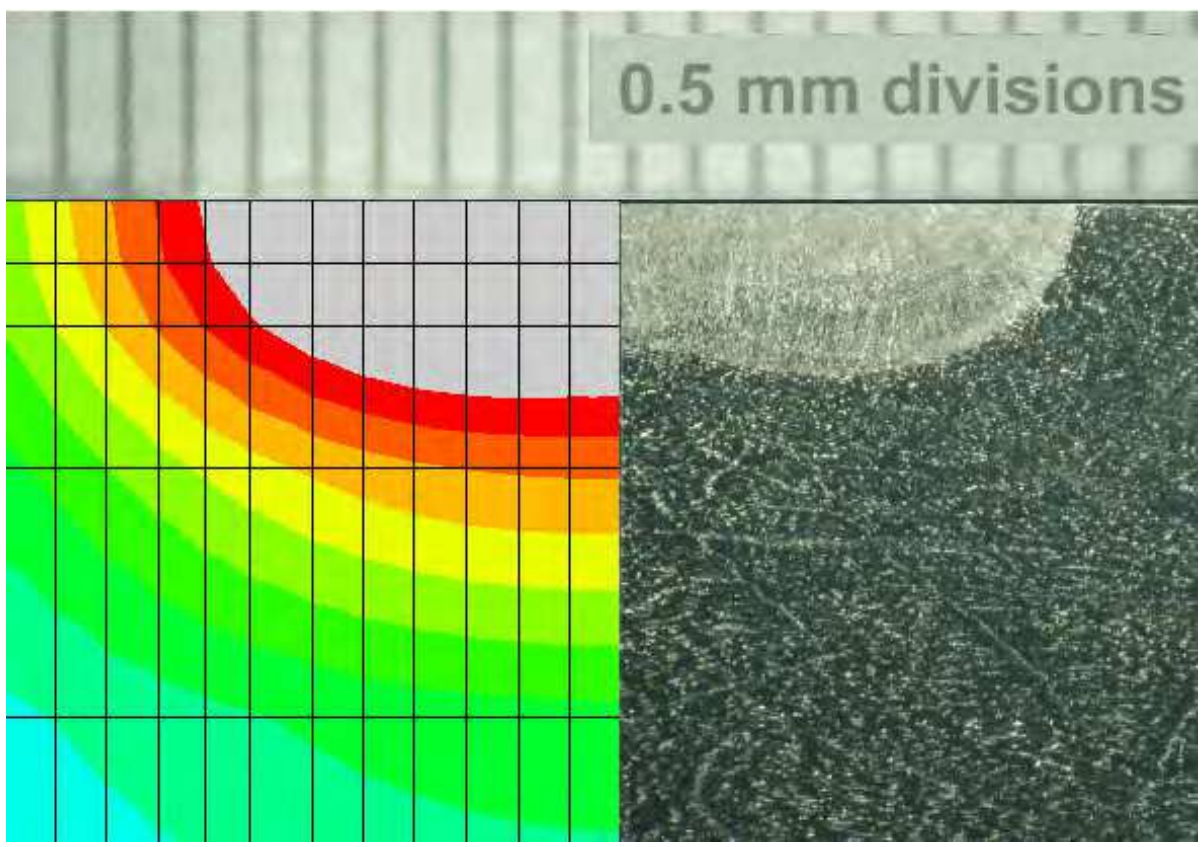

Fig. 11. Transverse section 2 ( 25\% along bead) through weld bead (Analysis B).

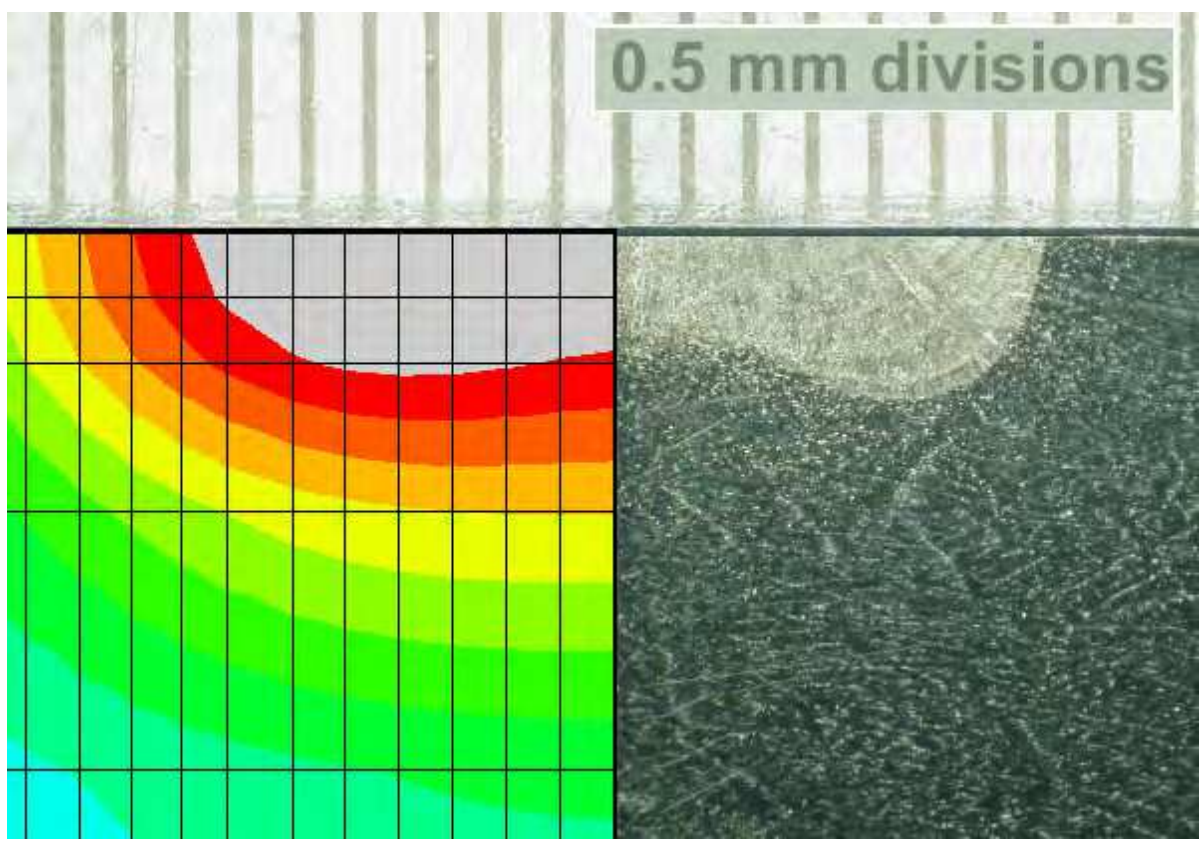

Fig. 12. Transverse section 3 (mid-length) through weld bead (Analysis B). 


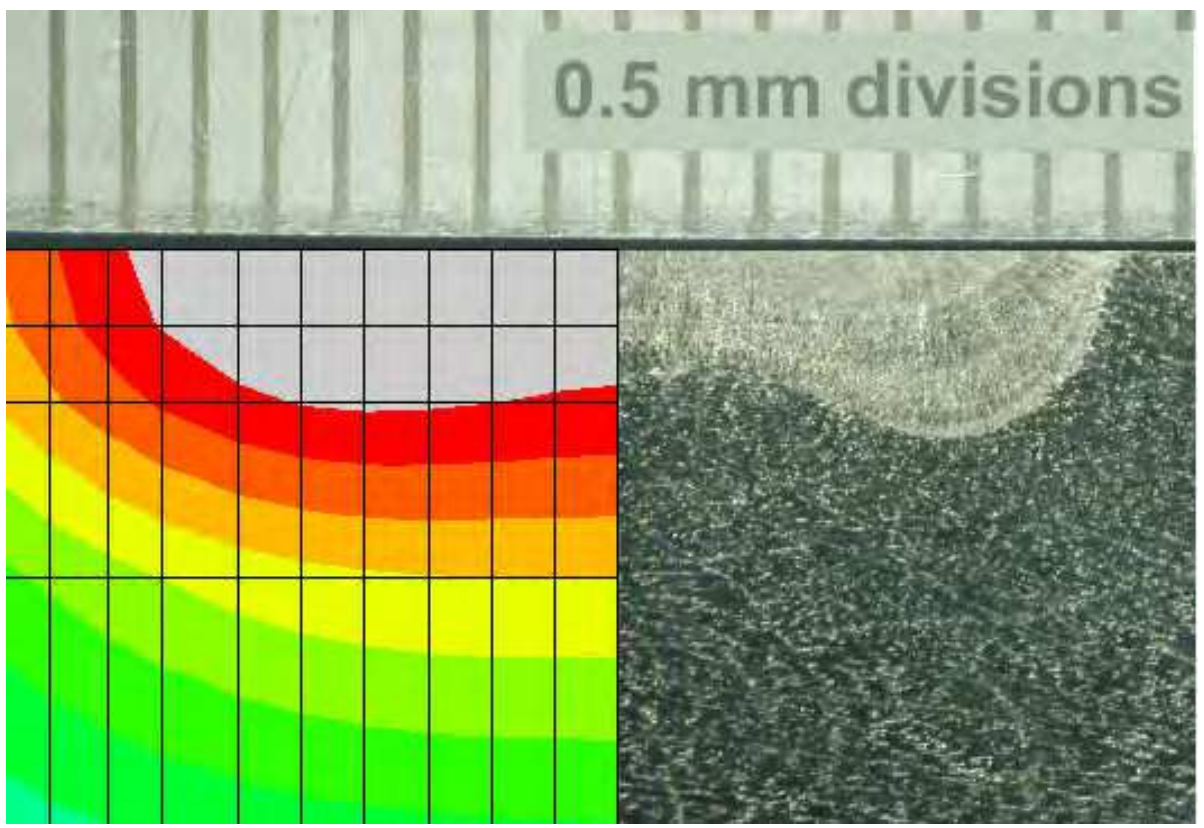

Fig. 13. Transverse section 4 ( $75 \%$ along bead) through weld bead (Analysis B).

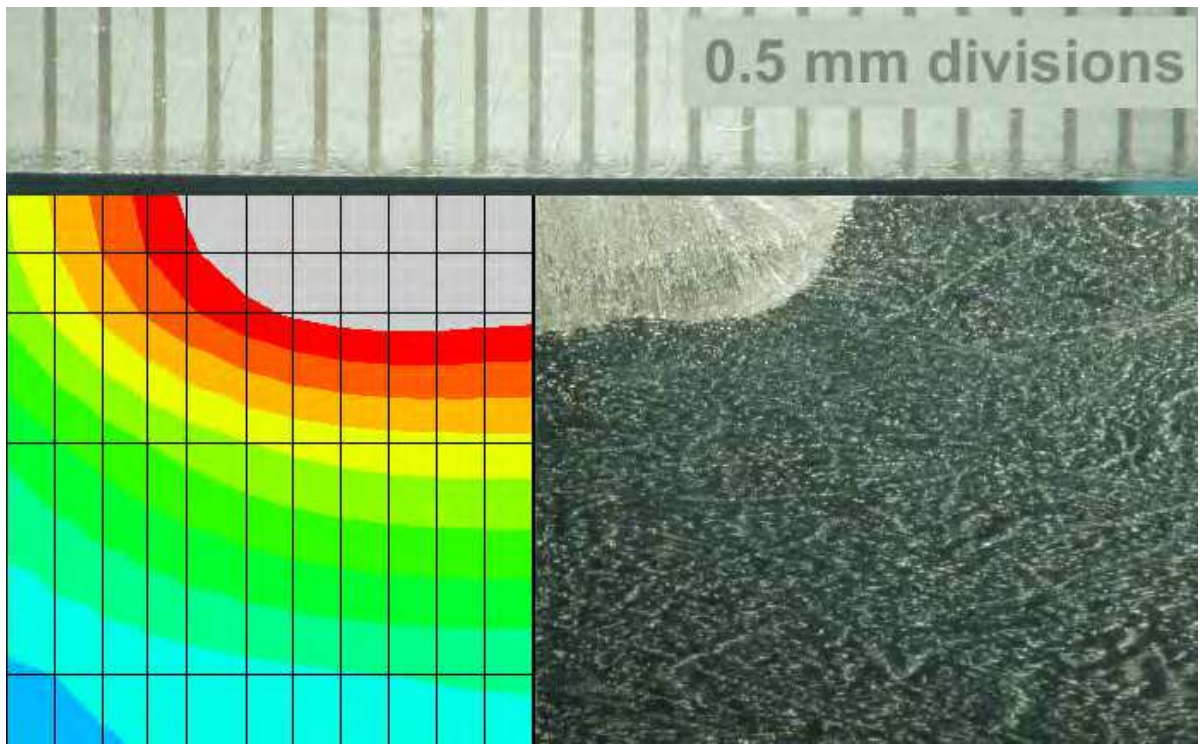

Fig. 14. Transverse section 5 (stop-end) through weld bead (Analysis B). 


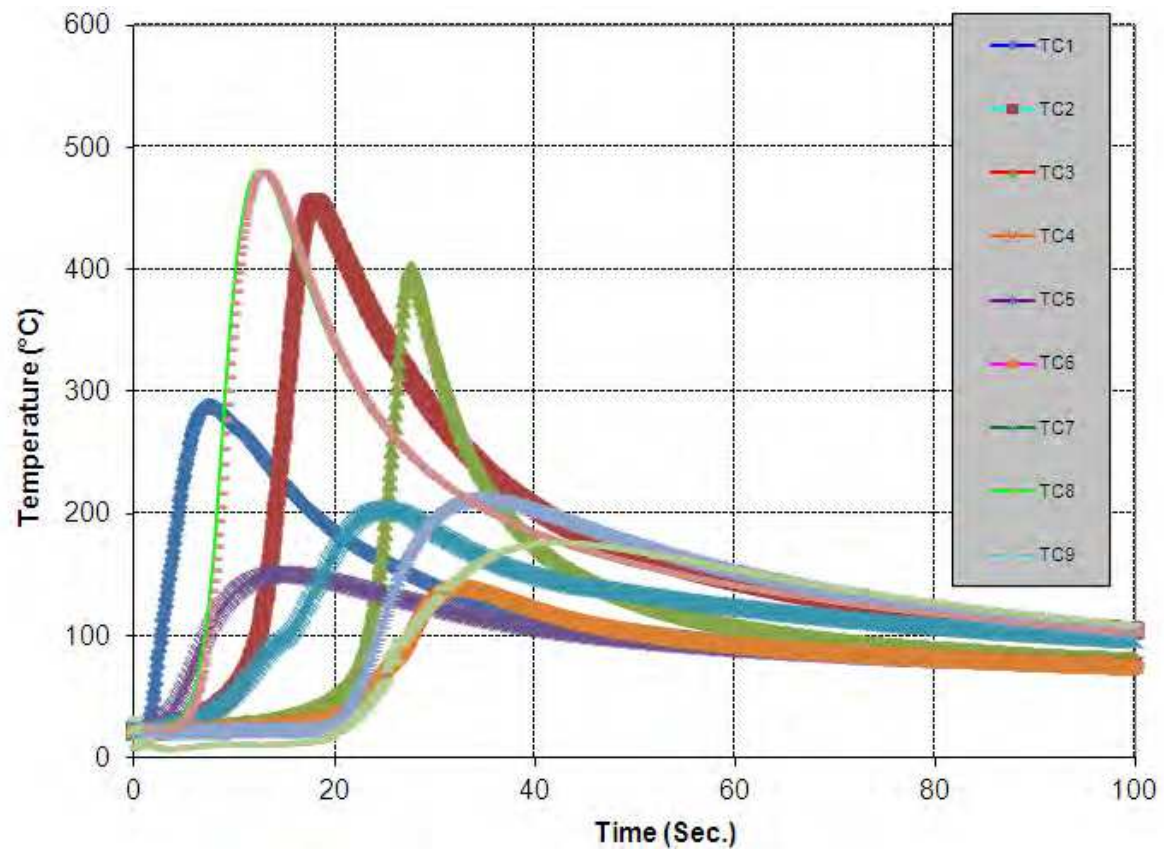

Fig. 15. Thermocouple measurements

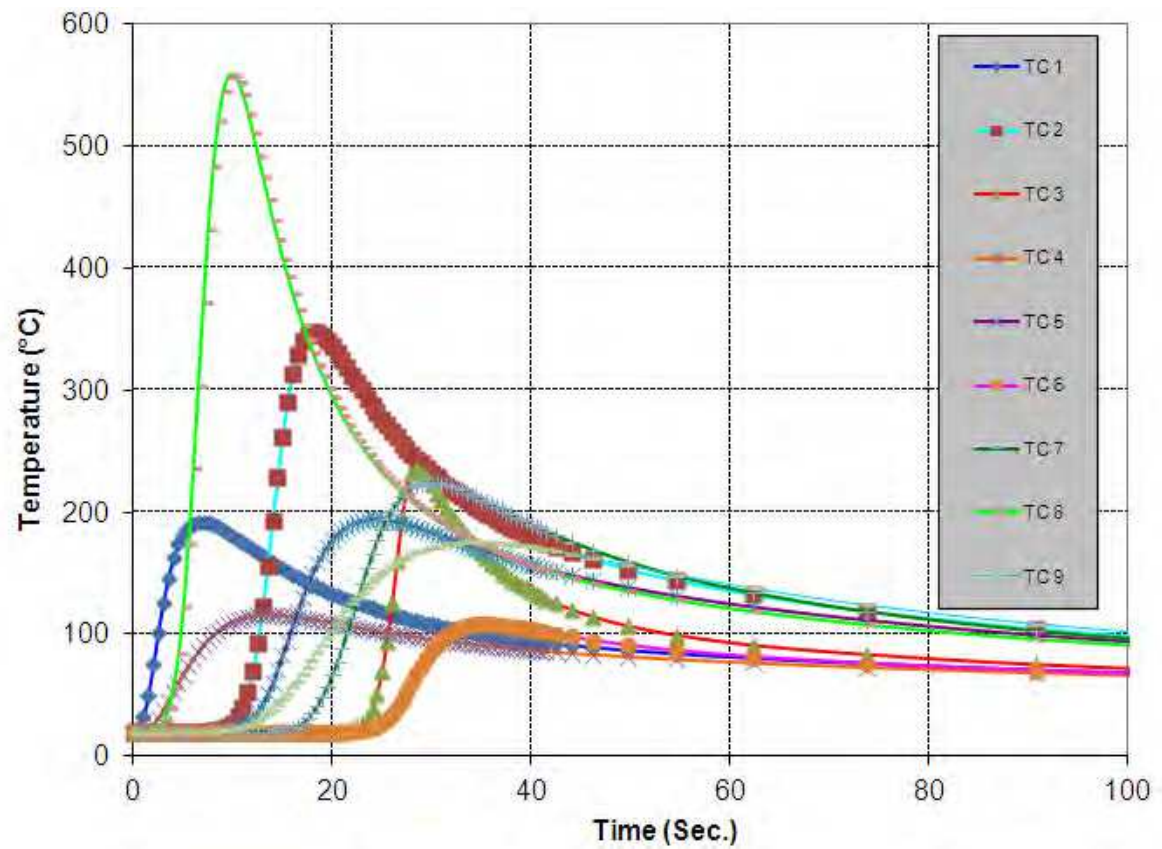

Fig. 16. Temperature predictions (Analysis B). 

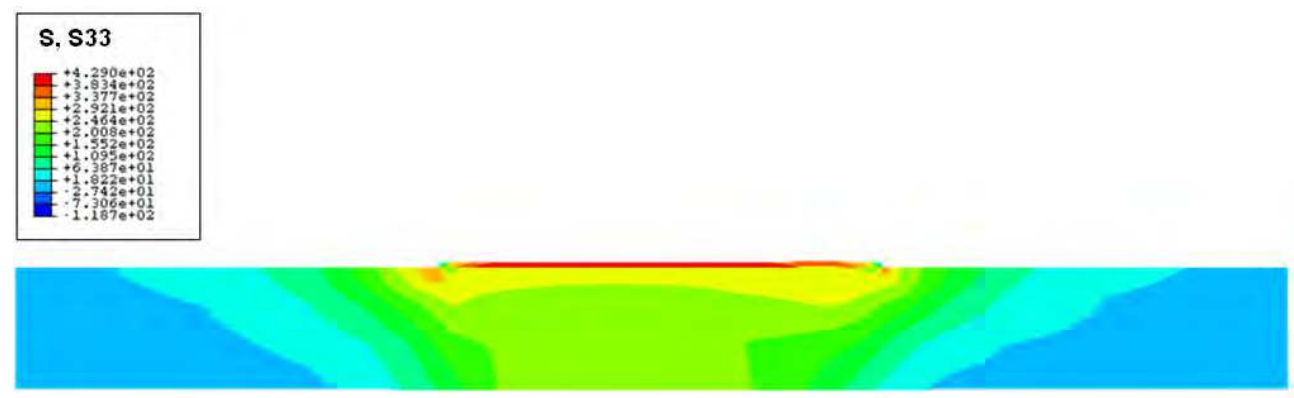

Fig. 17. Longitudinal stress (MPa); mixed hardening (Analysis B).
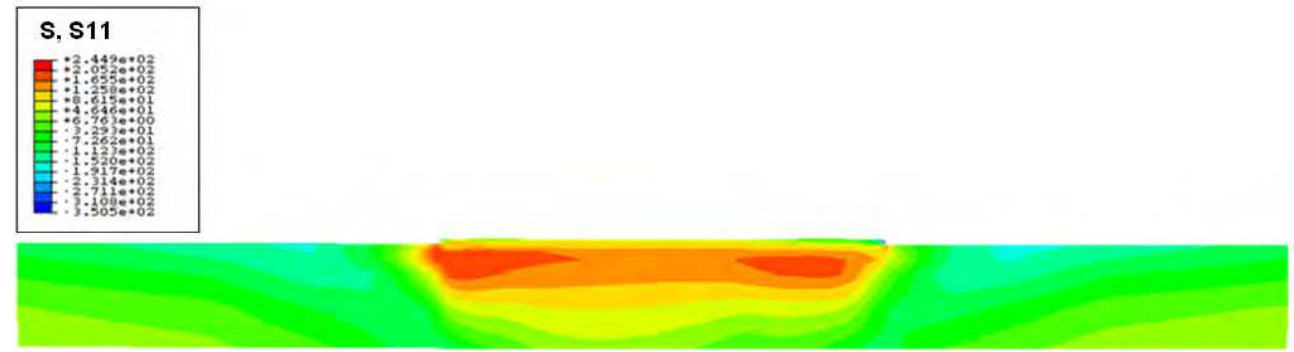

Fig. 18. Transverse Stress (MPa); mixed hardening (Analysis B).

Two separated analyses were completed to examine different heat source and hardening models. The first analysis utilize 2D Gaussian ellipse moving heat source with isotropic hardening. The second analysis utilize 3D Gaussian ellipsoidal moving heat source with both linear kinematic hardening and nonlinear isotropic/kinematic hardening, with an annealing temperature of $850^{\circ} \mathrm{C}$.

The predictions of transient temperatures and the extent of the melted zone are first compared with thermocouple measurements made during welding, and with the results of destructive metallography. The predicted residual stresses are then presented in order to identify the effects on the predicted residual stresses of the material hardening model, global heat input, mechanical and thermal boundary conditions, and the handling of high temperature inelastic strains.

Due to the absence of an effective heat source fitting tool within ABAQUS, the Gaussian ellipsoidal arc parameters $a, b, c_{1}$, and $c_{2}$ were calibrated by performing a set of manual iterative transient temperature analyses, which were labour intensive and not very effective.

It appears that the use of isotropic hardening leads to over-conservative predictions of stresses, particularly in the longitudinal direction (refer to Fig. 19). Moving from isotropic to nonlinear isotropic/kinematic or linear kinematic hardening reduces the predicted stresses. 


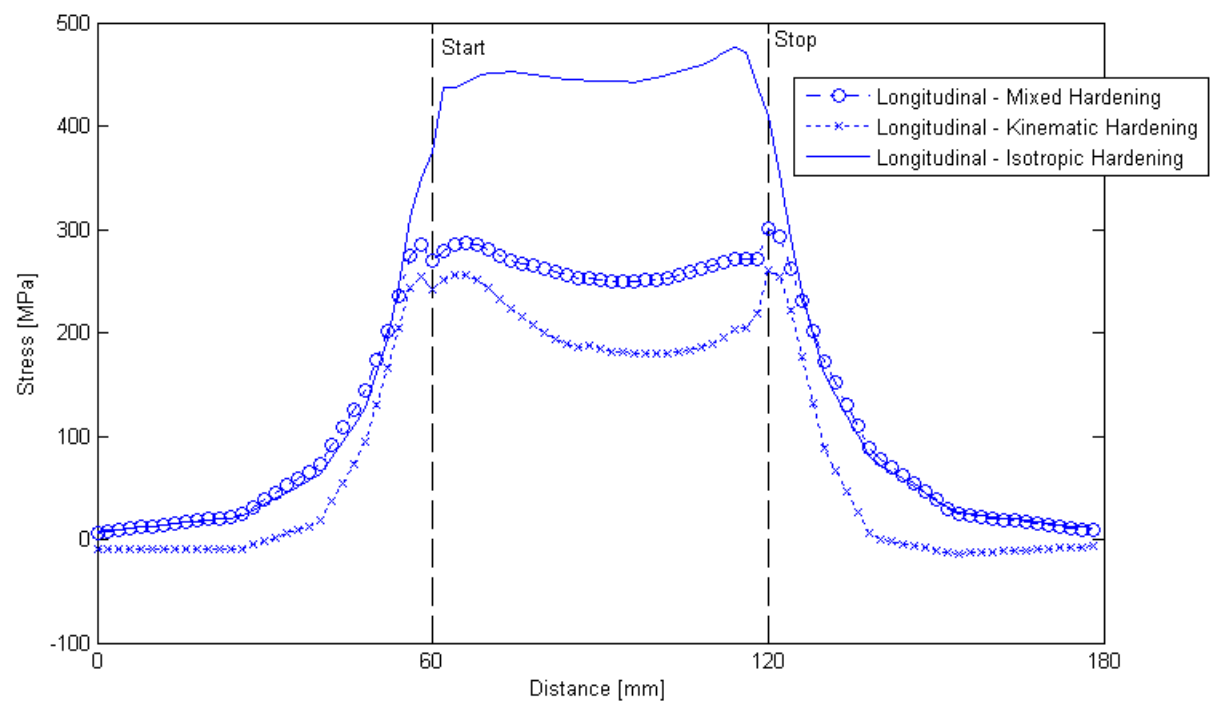

Fig. 19. Longitudinal stresses along section $2 \mathrm{~mm}$ below top surface of plate (Analyses A and B).

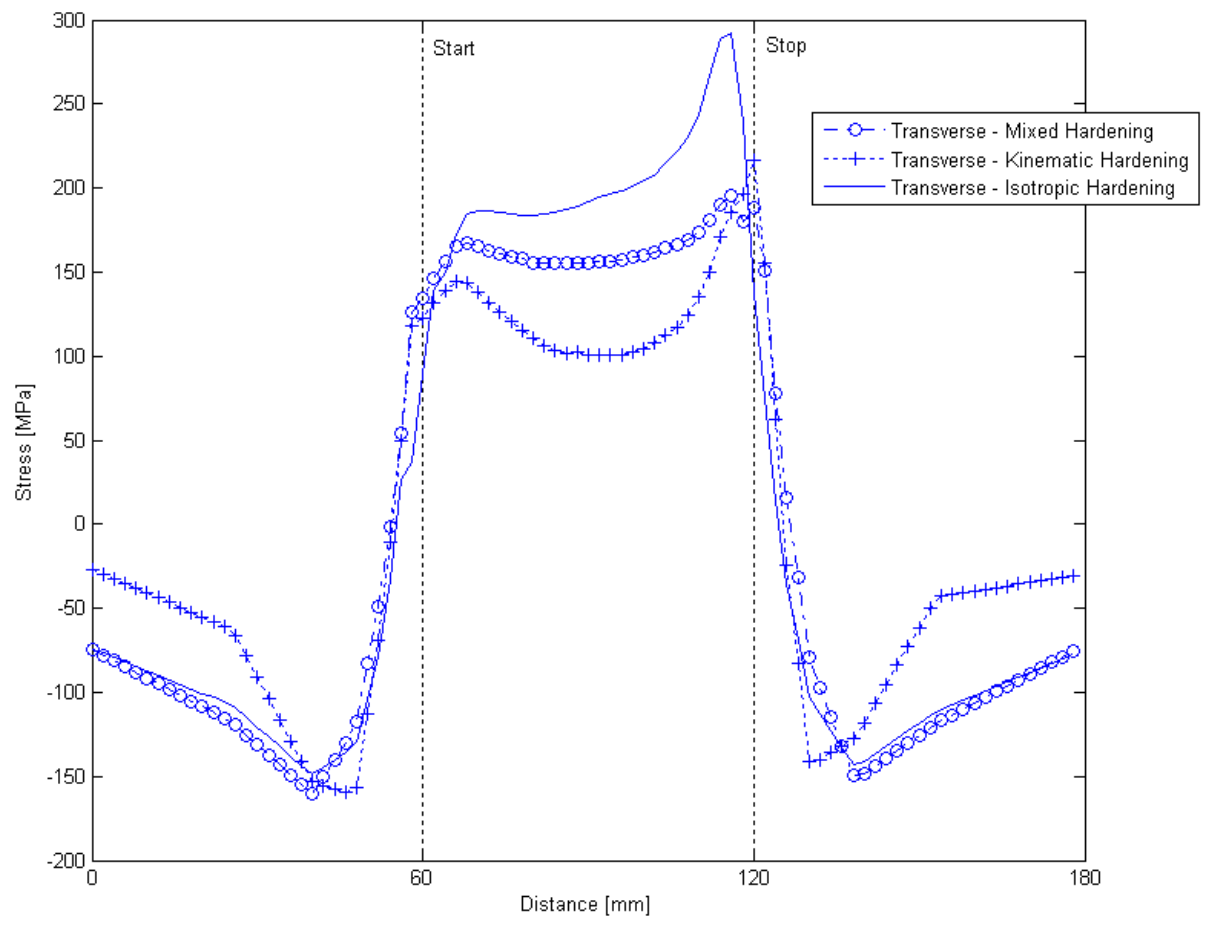

Fig. 20. Transverse stresses along section $2 \mathrm{~mm}$ below top surface of plate (Analyses A and B). 


\section{Austenite decomposition kinetics for steels}

The estimation of welding residual stresses in thick-section ferritic steel has been less successful than in austenitic stainless steel, largely due to the complexities associated with the solid state phase transformations that occur in multipass welding [1-3, 18-22]. To predict residual stresses in ferritic steels, a phase transformation kinetics model is therefore required for prediction of microstructure evolution. There is more than one model available to address phase transformations in ferritic steels [23-27]. In this section, we focused on one kind of model, namely, Li's model [25]. Li's model is a semi-empirical model for hardenable steels developed by Kirkaldy and Venugopalan [23, 27], and later refined by Li et al. This model is based on a phenomenological approach and on equations of the kinetic-chemical type. The equation is generally written as follow:

The austenite can, during cooling, transform into ferrite, pearlite, bainite and martensite. According to the Li's model, austenite decomposition is characterised as follows:

$$
\frac{d X}{d t}=F(G, T, C) X^{0.4(1-X)}(1-X)^{0.4 X}
$$

Where $X$ is the volume fraction of the transformation product at a given instant of time, $G$ is the ASTM grain size number, $C$ is chemical composition, and and $T$ the absolute temperature.

Austenite is stable at temperatures above the $A e_{3}$ (equilibrium temperature for austenitization end) and is unstable below the $A e_{3}$ line. As the temperature drops below the $A e_{3}$, ferrite begins to form. For the austenite-ferrite decomposition, the function $F$ is expressed by:

$$
F(G, T, C)=\frac{2^{0.41 G}\left(A e_{3}-T\right)^{3} \exp (-27500 / R T)}{\exp (-4.25+4.12 C+4.36 M n+0.44 S i+1.71 N i+3.33 C r+5.19 \sqrt{M o})}
$$

Where, $R$ is the gas constant. For temperatures below eutectoid, and depending upon the cooling rate, the untransformed austenite will tend to decompose to pearlite. For the austenite-pearlite decomposition, the function $F$ is expressed by:

$$
F(G, T, C)=\frac{2^{0.32 G}\left(A e_{1}-T\right)^{3} \exp (-27500 / R T)}{\exp (1.0+6.31 C+1.78 M n+0.31 S i+1.12 N i+2.70 C r+4.06 M o)}
$$

where $A e_{1}$ is quilibrium temperature for austenitization start. When the bainite-start temperature $B_{s}$ is reached, in this empirical theory, the pearlite is assumed to continue to form bainite at a rate given by:

$$
F(G, T, C)=\frac{2^{0.29 G}(B s-T)^{2} \exp (-27500 / R T)}{\exp (-10.23+10.18 C+0.85 M n+0.55 N i+0.90 C r+0.36 M o)}
$$

The martensite transformation is described by the Koistinen-Marburger [28] relationship.

$$
X(T)=1-\exp \left(-b\left(M_{s}-T\right) \text { for } T<M_{s}\right.
$$


There are only two parameters (exponent $b$ and martensite start temperature $M_{s}$ ) for this model.

The critical temperatures $A e_{3}, A e_{1}, M_{s}$ and $B_{s}$ are calculated either from thermo-dynamic software, such as MTDATA [29] or from empirical formula [25]. Figures 21 and 22 show two typical phase diagram calculated by MTDATA.

Other researchers have used Kirkaldy based equations to model microstrural evolutions during welding or forming processes, for example Watt et al. [26], Henwood et al. [30] and Akerstrom et al. [31], Lee et al. [32, 33].

Traditionally, the kinetics of transformation is typically described by a standard equation known as the Kolmogorov-Johnson-Mehl-Avrami equation [34-38], named after the individual researchers who derived it. The KJMA equation has been used by many authors to describe phase fraction change $[39,40]$. Other methods to model phase transformation include phasefield simulation [41], neural network [42], Monte Carlo simulation [43], etc.

In Li's model a constant grain size is used. Figures 23-25 show continuous cooling transformation (CCT) diagram predicted by using Li's model for SA508 Grade 3 for three different grain sizes [2]. It can be seen that the austenite grain size has significant effect on CCT curves. Further work is in progress in which the author is investigating the phase transformation kinetics incorporating austenite grain growth.

\section{Weld residual stress analysis including phase transformation effects}

The volume changes that occur in steels as they are heated and cooled can be inferred from dilatometry, where the change in length of an unloaded specimen is measured as a function of temperature. Figure 26 illustrates such an experiment - the upper straight line represents the expansion of the body-centred cubic phase (ferrite, bainite, martensite) and the lower line that of austenite $(\gamma)$. Data at locations between the upper and lower lines correspond to the coexistence of the parent and product phases. The transformations occurred at different temperatures upon heating and cooling. The transformation temperature is a function of the cooling rate, steel composition and austenite grain size. The measured coefficient of thermal expansion is larger for austenite $\left(\sim 23 \times 10^{-6} \mathrm{~K}^{-1}\right)$ than for ferrite $\left(\sim 15 \times 10^{-6} \mathrm{~K}^{-1}\right)$. As a consequence, the volume change due to transformation is greater during cooling than during heating. The volume expansion due to the transformation of austenite can partly compensate for thermal contraction strains arising as a welded joint cool. In this section, some finite element modelling cases have been presented. Predictions are compared and rationalised alongside measurements obtained by neutron diffraction.

The thermal analysis is followed by a mechanical analysis in a sequentially coupled model. The total strain rate can be partitioned as follows:

$$
\dot{\varepsilon}=\dot{\varepsilon}^{e}+\dot{\varepsilon}^{p}+\dot{\varepsilon}^{t h}+\dot{\varepsilon}^{t r}+\dot{\varepsilon}^{t p}
$$

where $\dot{\varepsilon}, \dot{\varepsilon}^{e}, \dot{\varepsilon}^{p}, \dot{\varepsilon}^{\text {th }}, \dot{\varepsilon}^{\text {tr }}, \dot{\varepsilon}^{\text {tp }}$ are total strain rate, elastic strain rate, plastic or viscoplastic strain rate, thermal, transformation (i.e., volume change) and transformation plasticity, strain rates, respectively. 


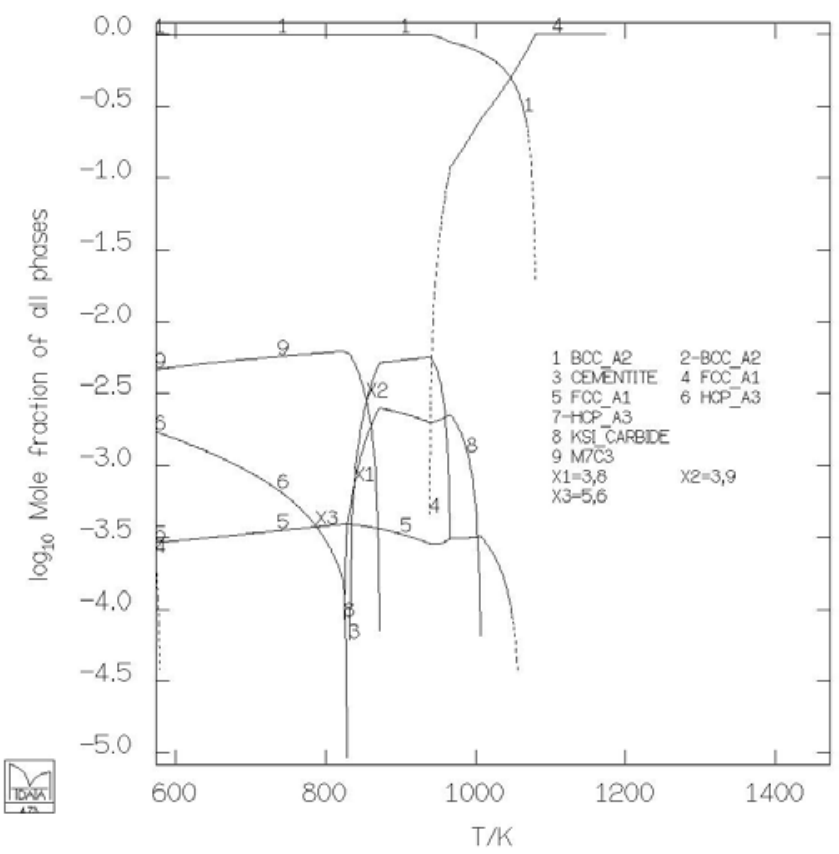

Fig. 21. Equilibrium mole fractions of phases versus temperature for SA508
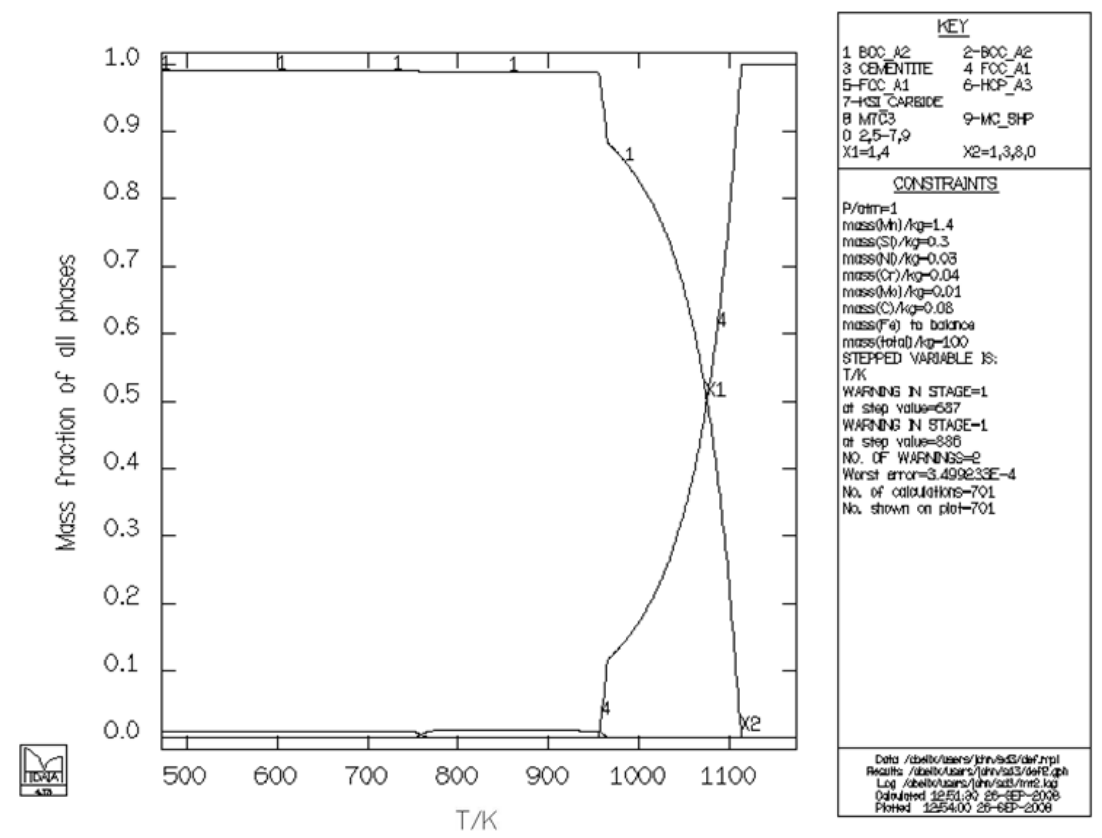

Fig. 22. Equilibrium mass fractions of phases versus temperature for SD3 


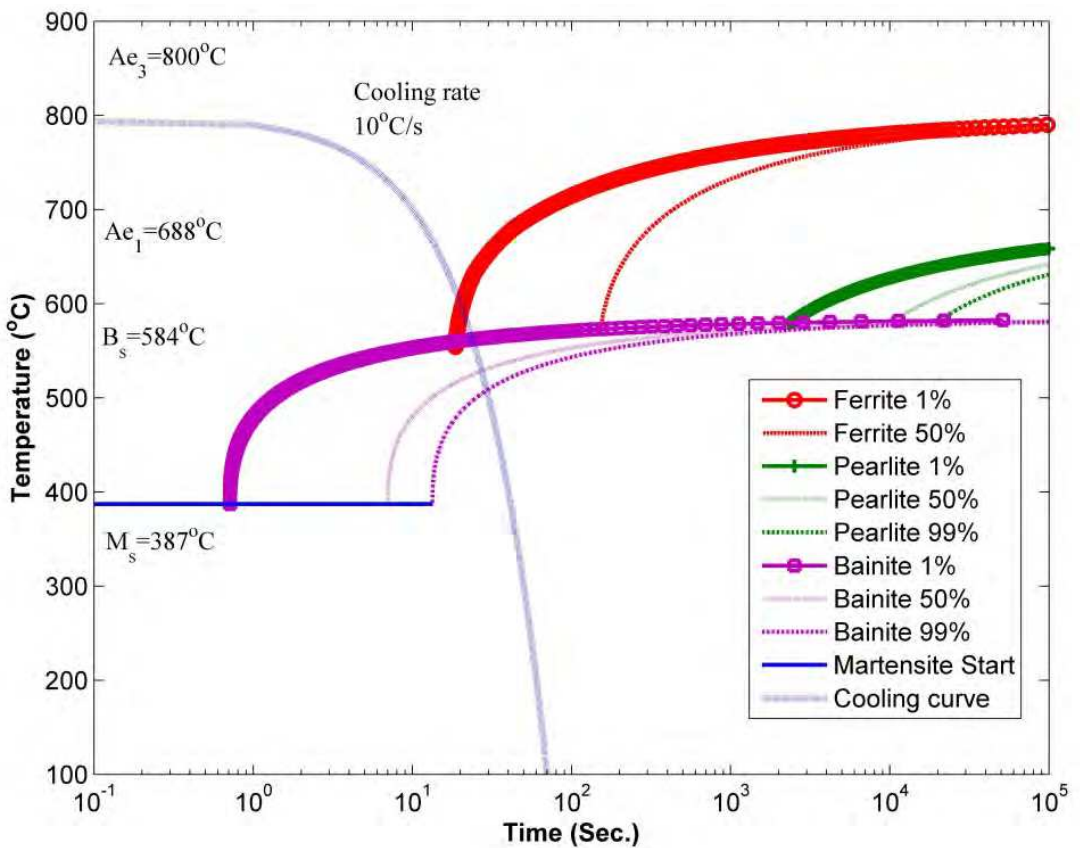

Fig. 23. Predicted CCT curve for SA508, grain size is 10 micrometers

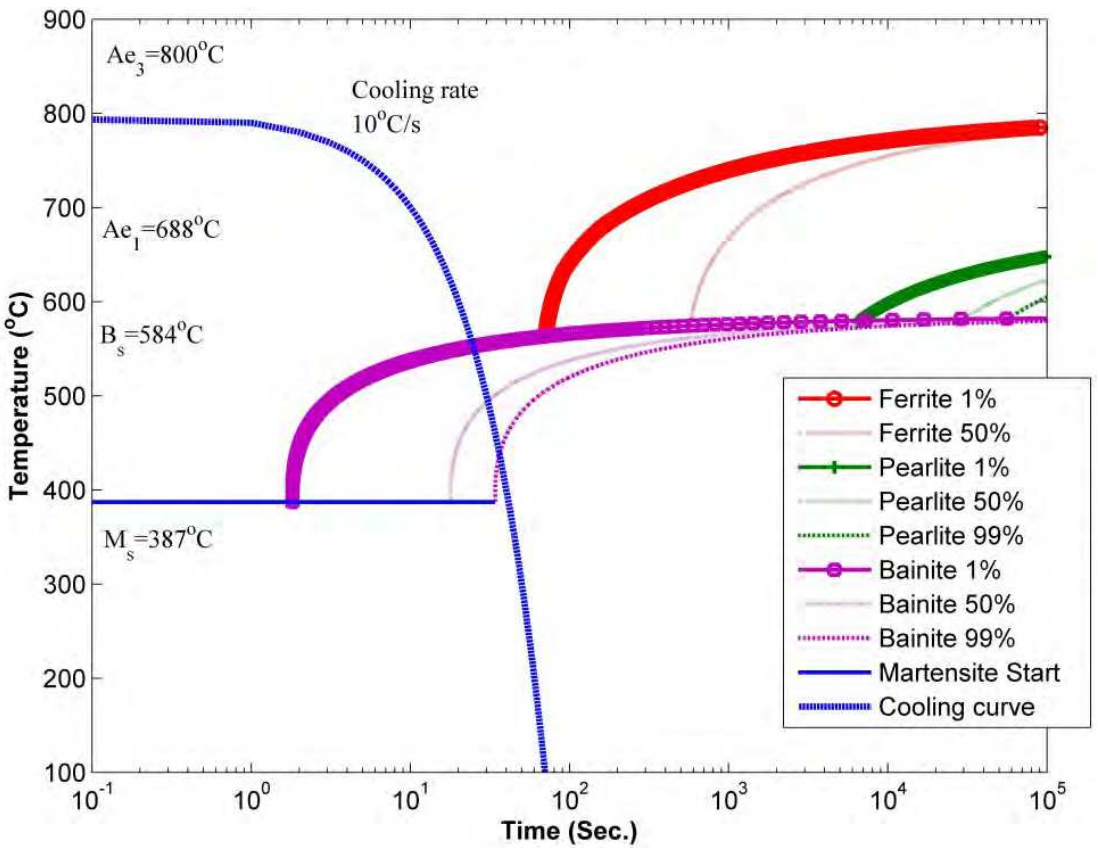

Fig. 24. Predicted CCT curve for SA508, grain size is 50 micrometers 


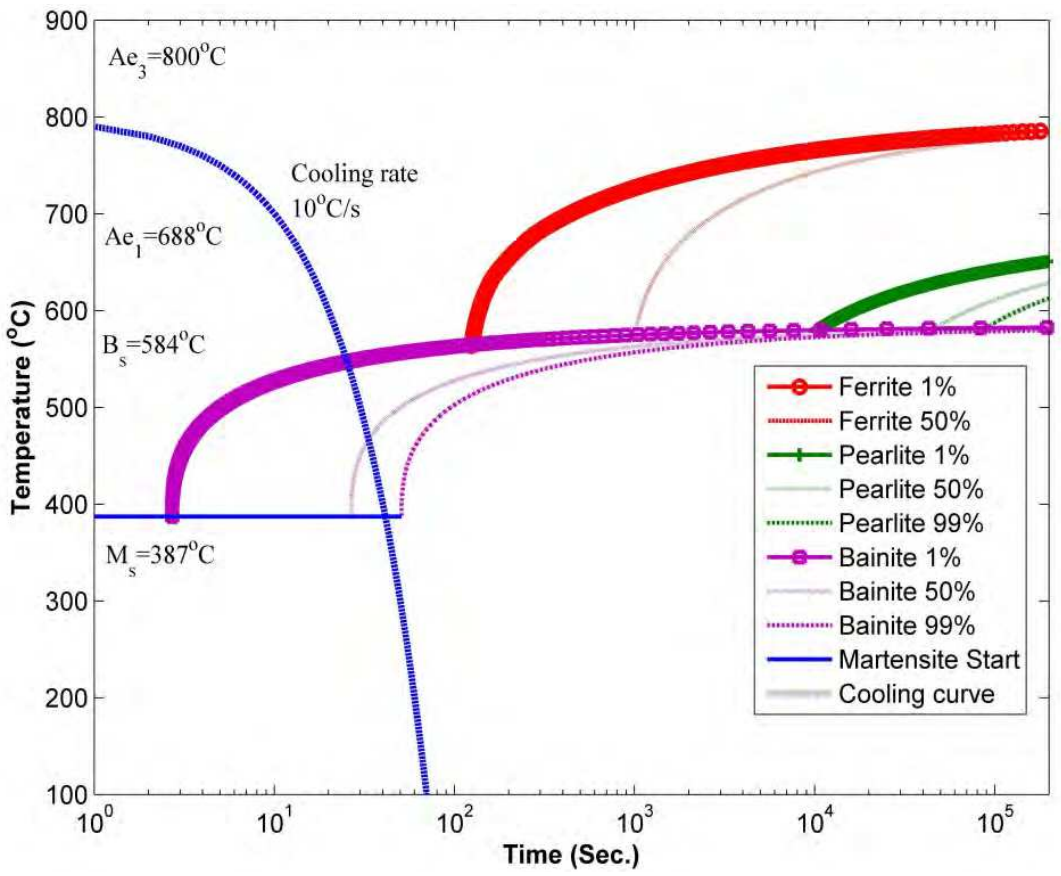

Fig. 25. Predicted CCT curve for SA508, grain size is 100 micrometers

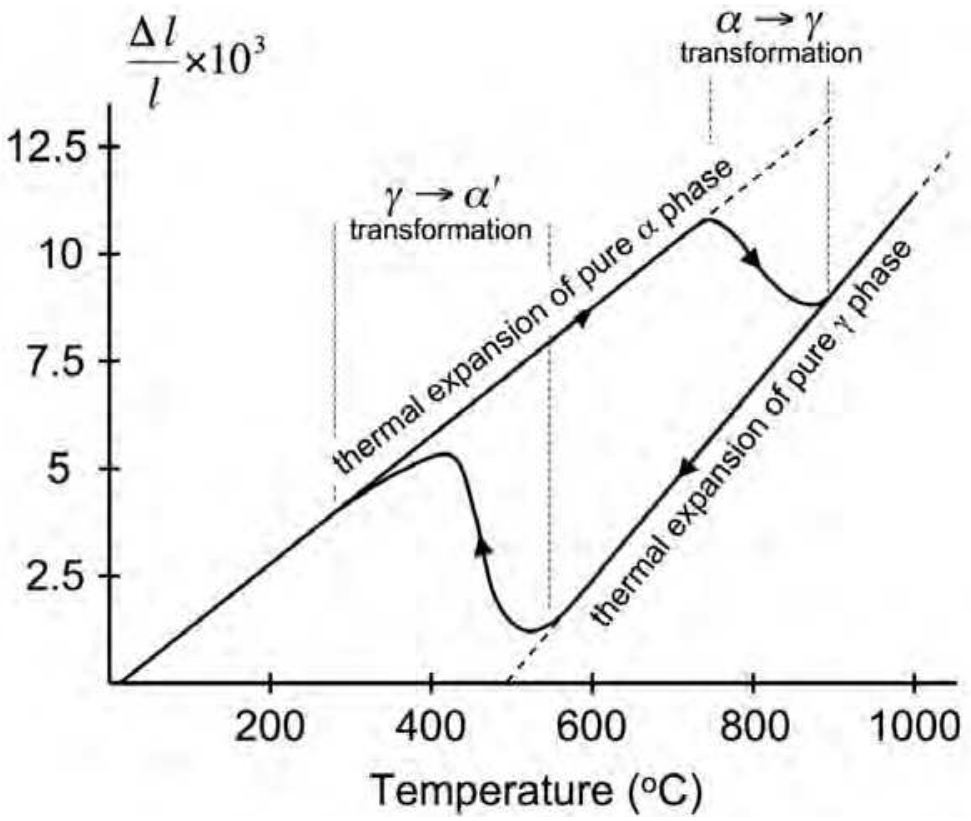

Fig. 26. Dilatometric diagram of SA508 steel heated at $30 \mathrm{~K} \mathrm{~s}^{-1}$ and cooled at $2 \mathrm{~K} \mathrm{~s}^{-1}[1,2]$. 
The thermal strain rate $\dot{\varepsilon}^{\text {th }}$ and transformation strain rate $\dot{\varepsilon}^{\text {tr }}$ can be expressed as:

$$
\begin{gathered}
\dot{\varepsilon}^{t h}=\left(X_{A} \alpha_{A}+X_{F} \alpha_{F}\right) \dot{T} \cdot 1 \\
\dot{\varepsilon}^{t r}=\varepsilon^{t r^{*}} \dot{X}_{F} \cdot 1
\end{gathered}
$$

Where, $X_{A}, X_{F}$ are the volume fractions of austenite and ferrite phases, respectively, $\alpha_{A}, \alpha_{F}$ are the thermal expansion coefficients of the corresponding phases, $\varepsilon^{t^{*}}$ is the dilatation due to austenite decomposition, $\mathbf{1}$ is the second order identity tensor.

Each phase has its own mechanical properties for plasticity, i.e., yield stress and a strain hardening law. Generally, applying a linear mixture law to the mixture of all phases gives:

$$
\sigma^{y}(T)=\sum_{\text {phases }} X_{i} \sigma_{i}^{y}(T)
$$

Leblond et al [44] considered two types of phases, one is a hard phases or alpha phase (mixture of ferrite phases); the other is a soft phase or gamma phase (austenite). A non linear mixture law was used between hard phases and soft phase.

\subsection{Case study: single pass weld}

This section describes the finite element analyses of two rectilinear single pass welding plates $(375 \times 200 \times 12 \mathrm{~mm})$ prepared from the high strength steel Weldox 960 [2, 18]. A 5-mmdeep " $\mathrm{V}$ " groove was machined along the center of each plate, with an included angle of 60 deg, into which a single weld bead of either OK75.78 or LTTE was deposited using manualmetal arc welding. The welding was performed in the down hand position with a heat input between 2.2 and $2.5 \mathrm{~kJ} \mathrm{~mm}^{-1}$, while a preheat temperature of $125^{\circ} \mathrm{C}$ was used and the plates were restrained by clamping during welding. The compositions of the two filler materials and the parent material are given in Table 1.

\begin{tabular}{lccccccc}
\hline Material & $\mathrm{C}$ & $\mathrm{Si}$ & $\mathrm{Mn}$ & $\mathrm{Cr}$ & $\mathrm{Ni}$ & $\mathrm{Mo}$ & $\mathrm{Cu}$ \\
\hline Weldox 960 & 0.20 & 0.50 & 1.6 & 0.7 & 2.0 & 0.7 & 0.3 \\
OK 75.78 & 0.05 & 0.19 & 2.0 & 0.4 & 3.1 & 0.6 & - \\
LTTE & 0.07 & 0.20 & 1.3 & 9.1 & 8.5 & - & - \\
\hline
\end{tabular}

Table 1. Approximate compositions of base plate and filler metals in weight percent

In this work, prior to running SYSWELD models, the transformation temperatures of the parent steel and weld metals were estimated according to software available via MTDATA [29]. Estimates for the elevated-temperature yield stress of each weld metal were obtained by examining the results of the Satoh tests and assuming that once the stress level had reached yield, and prior to the commencement of a transformation, the stress that is recorded in a Satoh test can be assumed to be representative of the yield locus. A roomtemperature value for the yield stress of the parent material was obtained from the manufacturer's data sheets. At intermediate temperatures, values for the yield stress were 
either interpolated or extrapolated. For each weld, a transient 3-dimensional analysis was carried out. A 3D half model, invoking symmetry along the centre of the weld bead is constructed, as shown in Fig. 27. Complex arc and weld pool phenomena were not considered, as is generally the case for the numerical prediction of weld residual stresses. However, a double-ellipsoid heat source was used to represent the welding arc, and this was calibrated using the in-built heat-source fitting tool within SYSWELD, by comparing the predicted geometries for the fusion zones and HAZ's with those measured from macrograph sections through each welded plate. In each case, a 3-dimensional simulation was carried out using 48,240 eight-noded brick elements in both the transient-thermal and mechanical analyses. In order to account for the effects of annealing, the history of any element, including any plastic strain, was erased if the peak temperature exceeded the temperature of fusion. Otherwise, the model was configured to simulate the welding conditions as accurately as possible. Figure 28 presents fusion boundary at mid-length transverse section through weld pass on the plate.

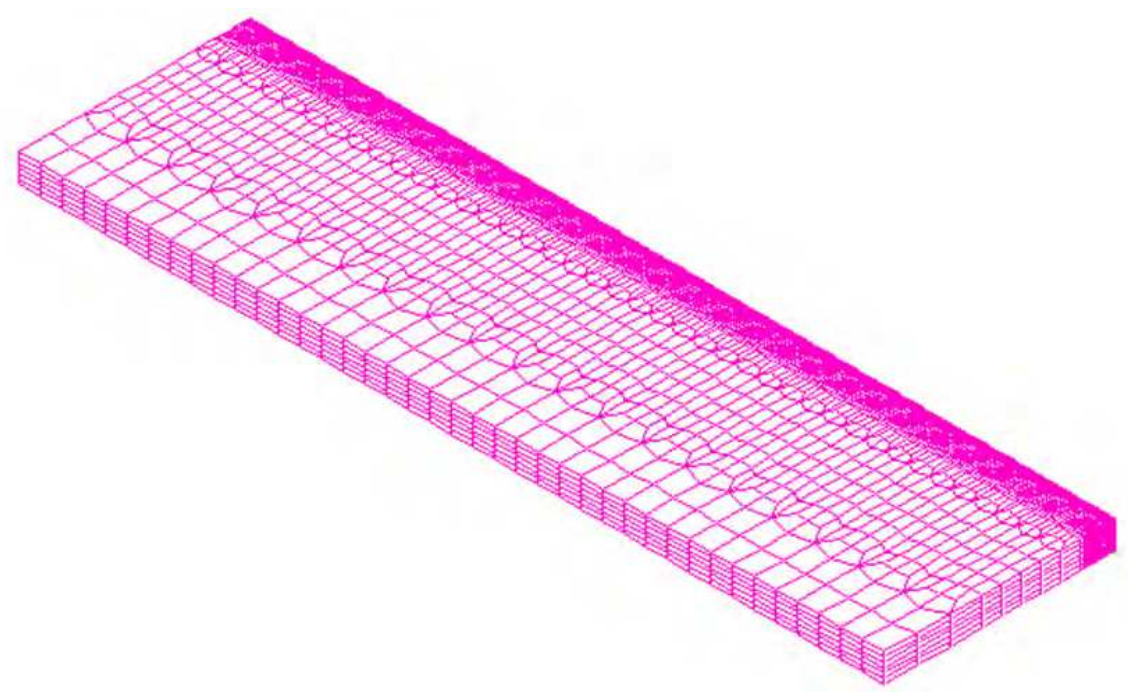

Fig. 27. Mesh of the plate being welded

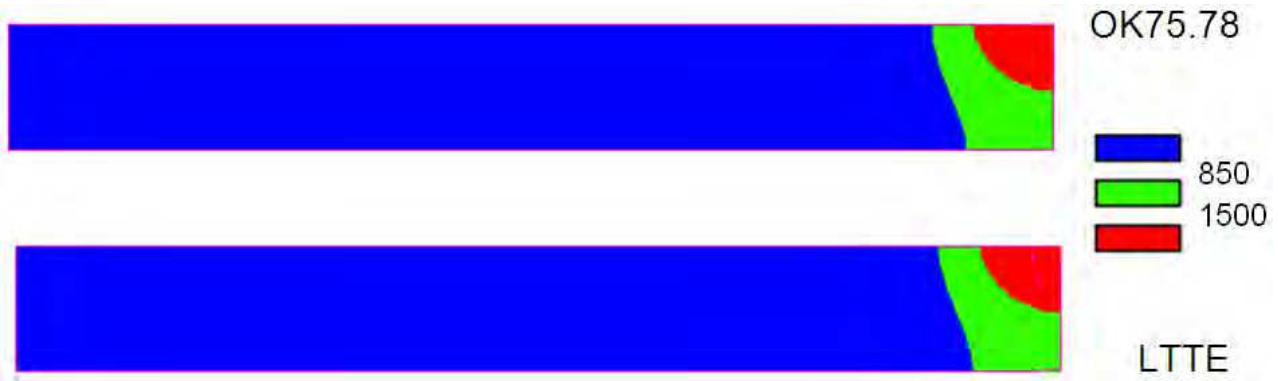

Fig. 28. Fusion zones produced for both cases. 
A comparison of the longitudinal residual stress distributions predicted by SYSWELD with those that were measured by neutron diffraction is given in Fig. 29. The neutron diffraction results (top) show that, when compared to OK75.78, the LTTE weld metal introduces significant longitudinal compressive residual stresses within the fusion zone. As discussed above, this is consistent with LTTE having a lower transformation temperature than OK75.78. Furthermore, the peak tensile residual stresses, which for both welds appear to arise just outside the HAZ, are somewhat lower in the weld made with LTTE, and they arise over a smaller region. In the weld made with the OK75.78 filler material, the phase transformations that have taken place within the HAZ and fusion zone still have significantly reduced the residual stresses to levels that are below the peak tensile stresses found immediately outside the HAZ. Since the transformation temperatures of the weld metal and parent material are similar in this case (Weldox transforms at around $460{ }^{\circ} \mathrm{C}$ compared to $440{ }^{\circ} \mathrm{C}$ for diluted OK 75.78 [18]), these zones appear to behave similarly, and there is no discernible variation in residual stress with distance down the weld centre-line.
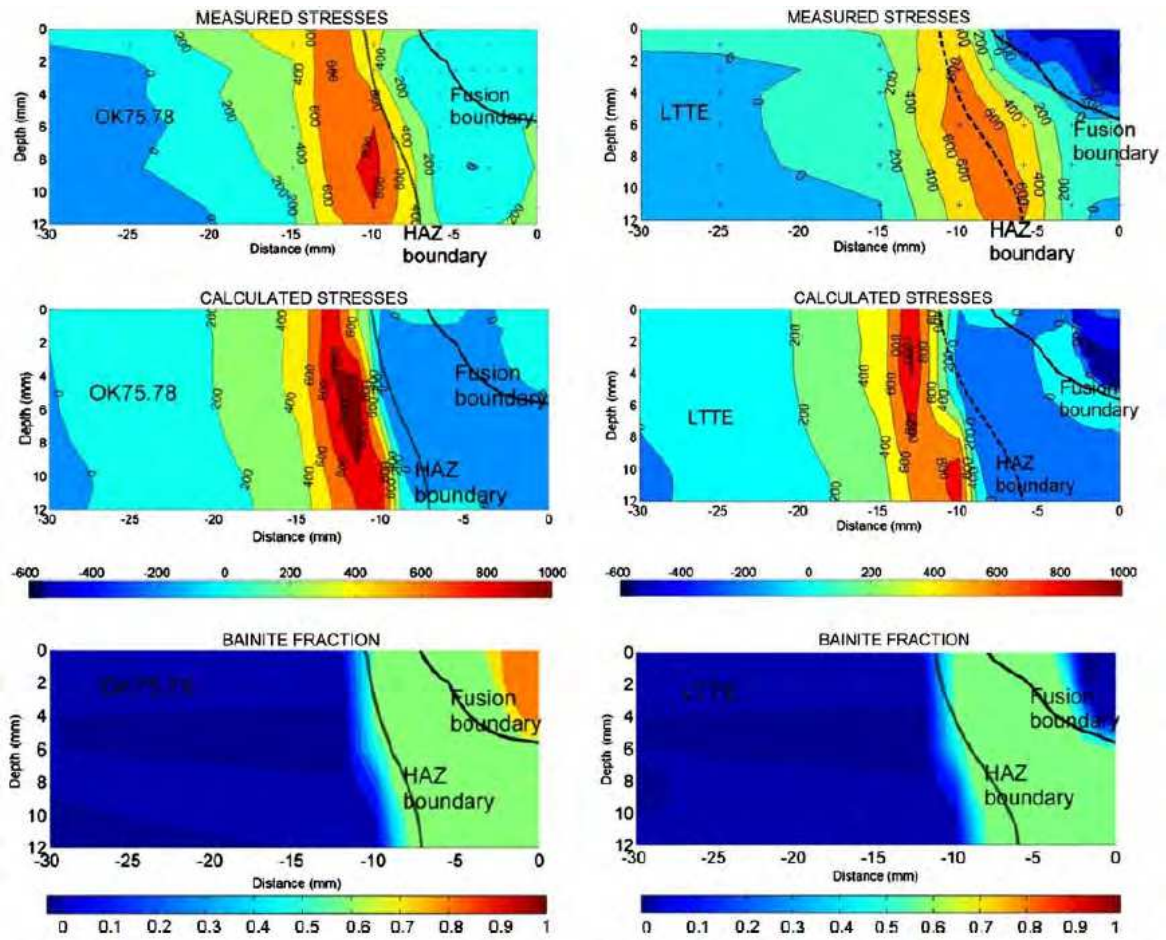

Fig. 29. Comparison of neutron diffraction measurements of longitudinal residual stress (top) in the near weld region as reported in Ref. 10 with the stress distributions predicted by SYSWELD (middle) for welds made using the OK75.78 filler metal (left) and the LTTE filler metal (right).The predicted proportions of bainite formed as a consequence of welding appear for each weld at the bottom of the figure. Note that very little bainite exists in the LTTE weld metal, because this is a martensitic alloy. Beyond the HAZ boundary, the bainite fractions are equal to zero, because no phase transformations took place at these locations during welding. All dimensions are in $\mathrm{mm}$ and all stresses are in $\mathrm{MPa}$. 
It is evident from Fig. 29 that the major features of the stress distributions have been predicted correctly for both filler metals. For example, it appears that the location of the peak tensile stresses is approximately correct in each case. Furthermore, the models have predicted that the OK75.78 filler metal will lead to relatively low stresses within and directly underneath the weld bead, and that the LTTE filler metal will introduce highly compressive residual stresses to the weld metal region at about the right level $(\sim-400 \mathrm{MPa})$. The magnitude of the tensile peak stresses, however, appears to be somewhat over-estimated by the SYSWELD models. This may be related to the limitations associated with using data from Satoh tests to estimate the yield locus. In both cases, isotropic hardening was assumed, but the authors also created models that assumed kinematic hardening and it was found that, for the single welding thermal cycle, there did not appear to be any notable sensitivity to the hardening model adopted.

Interestingly, SYSWELD predicts that the transformation temperature of the weld metal does not have a significant effect on the magnitude of the peak stresses beyond the HAZ, although a small reduction in the extent of the peak-stress region does appear to have been captured. It is possible, however, that the effects of the weld metal transformation temperature would have been predicted more accurately if the transformation strains within the fusion zone and HAZ had been represented faithfully. In this respect it should also be noted that variant selection has not been incorporated in the SYSWELD model. This means that only the volume part of the transformation has been accounted for. The anisotropic shear component may be significant, especially for transformations at low temperature, where the stress just prior to transformation will be large and thus may bias variant selection. This would increase the effectiveness of the transformation in reducing the residual stress. This effect will be reported subsequently.

While the overall agreement between the simple SYSWELD model trained only on the basis of Satoh tests and the neutron results is encouraging, the discrepancies between the models and the neutron diffraction measurements highlight the need for validation and improved understanding of the transformation behaviour. In this respect further in-situ synchrotron X-ray diffraction experiments, such as those described in another article [18], offer the potential for the quantification of phase fractions during any simulated welding thermal cycle that may be of interest, and they can also reveal the extent to which stress-induced transformation texture (or variant selection) may contribute to anisotropy in macroscopic transformation strains.

\section{Conclusion}

Mathematic modelling of austenitic (non-transforming) and ferritic (transforming) steel welds has been investigated by using finite element codes ABAQUS and SYSWELD. This is part of a research programme the author carried out at the University of Manchester, UK. The aim of the work is to understand welding residual stress by numerical modelling and neutron diffraction measurements.

Numerical studies of a single bead on plate austenitic steel weld suggest that the use of isotropic hardening leads to over-conservative predictions of stresses, particularly in the longitudinal direction. Moving from isotropic to nonlinear isotropic/kinematic or linear kinematic hardening reduces the predicted stresses. 
Numerical studies of a single pass ferritic steel welds show that phase transformation and transformation temperature have significant effects on residual stress. Neutron diffraction measurements supported numerical results. Utilities were developed within the finite element code ABAQUS to incorporate solid state phase transformations (micro-structural evolutions, phase dependent properties and volume changes) in welding residual stress analysis.

\section{Acknowledgements}

The author would like to acknowledge support from Rolls-Royce Marine, and the Stress \& Damage Characterisation (SDC) unit at the University of Manchester.

\section{References}

[1] Francis JA, Bhadeshia HKDH, Withers PJ. Welding residual stresses in ferritic power plant steels. Materials Science and Technology 2007;23:1009.

[2] Dai H, Francis JA, Keavey MA, Withers PJ. Modelling of Microstructural Evolution in Thick-Section Ferritic Steel Welds. Manchester: University of Manchester, 2008. p.28.

[3] Dai H, Francis JA, Turski M, Withers PJ. Weld Modelling and Material Models For Steels. Manchester: University of Manchester, 2007. p.42.

[4] Lindgren LE. Finite Element Modeling And Simulation Of Welding Part 1: Increased Complexity. Journal of Thermal Stresses 2001;24:141.

[5] Lai WM, Rubin D, Krempl E. Introduction to Continuum Mechanics (3rd Edition). Elsevier, 1996.

[6] Grong O. Metuallurgical Modelling of Welding. London: The Institute of Materials, 1997.

[7] Goldak J, Breigruine V, Dai N, Hughes E, Zhou J. Thermal Stress Analysis in Solids Near the Liquid Region in Welds. In: Cerjak H, editor. Mathematical Modelling of Weld Phenomena. London: The Institute of Materials, 1997. p.543.

[8] Murugan S, Rai S K, Kumar P V,. Temperature distribution and residual stresses due to multipass welding in type 304 stainless steel and low carbon steel weld pads. International Journal of Pressure Vessels \& Piping 2001;78:307.

[9] Parameswaran P, Paul V T, Vijayalakshmi M,. Microstructural evolution in a single pass autogenously welded 2.25Cr-1Mo steel. Trans. Indian Inst. Met. 2004;57:253.

[10] Fanous, Ihab FZ, Younan, Maher YA, Wifi, Abdalla S. 3-D finite element modeling of the welding process using element birth and element movement techniques. New York, NY, ETATS-UNIS: American Society of Mechanical Engineers, 2003.

[11] Wu CS, Yan F. Numerical simulation of transient development and diminution of weld pool in gas tungsten arc welding. Modelling and Simulation in Materials Science and Engineering 2004;12:13.

[12] Goldak J, Bibby M, Moore J, House R, Patel B. Computer modeling of heat flow in welds. Metallurgical and Materials Transactions B 1986;17:587.

[13] Dong P. Residual stresses and distortions in welded structures: a perspective for engineering applications. Science and Technology of Welding \& Joining $2005 ; 10: 389$. 
[14] Feng Z, Wang XL, Spooner S, Goodwin GM, Maziasz PJ, Hubbard CR, Zacharia T. A finite element model for residual stress in repair welds. Conference: American Society of Mechanical Engineers (ASME) pressure vessels and piping conference, Montreal (Canada), 21-26 Jul 1996; Other Information: PBD: 28 Mar 1996, 1996. p.Medium: ED; Size: 7 p.

[15] ABAQUS. User's Manual. Hibbit, Karsson and Sorenson, Inc., 2006.

[16] ESI-Group. SYSWELD, Theory Manuals. ESI UK, John Eccles House, The Oxford Science Park, Oxford., 2006.

[17] Dennis RJ, Leggatt NA, Gregg A. Optimisation of Weld Modelling Techniques: Beadon-Plate Analysis. ASME Conference Proceedings 2006;2006:967.

[18] Dai H, Francis JA, Stone HJ, Bhadeshia HKDH, Withers PJ. Characterizing Phase Transformations and Their Effects on Ferritic Weld Residual Stresses with X-Rays and Neutrons. Metallurgical and Materials Transactions A 2008;39:3070.

[19] Dai H, Keavey MA, Withers PJ. Modelling of Residual Stress in Thick-Section Ferritic Steel Welds Considering Phase Transformation Effects. Manchester: University of Manchester, 2009. p.34.

[20] Dai H, Francis JA, Withers PJ. Prediction of residual stress distributions for single weld beads deposited on to SA508 steel including phase transformation effects. Materials Science and Technology 2010;26:940.

[21] Dai H, Mark AF, Moat R, Shirzadi AA, Bhadeshia HKDH, Karlsson L, Withers PJ. Modelling of residual stress minimization through martensitic transformation in stainless steel welds. In: Cerjak H, Enzinger N, editors. Mathematical Modelling of Weld Phenomena 9. Graz: Technische Universitat Graz, 2010. p.239.

[22] Dai H, Moat R, Mark AF, Withers PJ. Investigation on transformation induced plasticity and residual stress analysis in stainless steel welds. ASME 2010 Pressure Vessels \& Piping Division / K-PVP Conference. Bellevue, Washington: ASME, 2010. p.PVP2010.

[23] Kirkaldy JS, Venugopalan D, Marder AR, Goldstein JI. Prediction of microstructure and hardenability in low alloy steels. In: Marder AR, Goldstein JI, editors. Phase Transformations in Ferrous Alloys. New York: AIME, 1984. p.125.

[24] Leblond JB, Devaux J. A new kinetic model for anisothermal metallurgical transformations in steels including effect of austenite grain size. Acta Materialia 1984;32:137.

[25] Li M, Niebuhr D, Meekisho L, Atteridge D. A computational model for the prediction of steel hardenability. Metallurgical and Materials Transactions B 1998;29:661.

[26] Watt D, Coon L, Bibby M, Goldak J, Henwood C. An algorithm for modelling microstructural development in weld heat-affected zones (part a) reaction kinetics. 1988;36:3029.

[27] Kirkaldy JS. Diffusion-controlled phase transformations in steels. Theory and applications. Scandinavian Journal of Metallurgy 1991;20:50.

[28] Koistinen DP, Marburger RE. A general equation prescribing the extent of the austenitemartensite transformations in pure iron-carbon alloys and plain carbon steels. 1959;7:59.

[29] National Physical Laboratory NPL. MTDATA Software. Teddington, UK, 2006.

[30] Henwood C, Bibby M, Goldak J, Watt D. Coupled transient heat transfer-microstructure weld computations (part b). 1988;36:3037. 
[31] Akerstrom P, Oldenburg M. Austenite decomposition during press hardening of a boron steel computer simulation and test. Journal of Materials Processing Technology, vol. 174:1-3. Journal of Materials Processing Technology, 2006.

[32] Lee SJ, Lee YK. Finite element simulation of quench distortion in a low-alloy steel incorporating transformation kinetics. Acta Materialia 2008;56:1482.

[33] Lee S-J, Pavlina EJ, Van Tyne CJ. Kinetics modeling of austenite decomposition for an end-quenched 1045 steel. Materials Science and Engineering: A 2010;527:3186.

[34] Avrami M. Kinetics of phase change: 1. General theory. Journal of Chemical Physics 1939;7:1103.

[35] Avrami M. Kinetics of phase change: 2. Transformation-Time Relations for Random Distribution of Nuclei. Journal of Chemical Physics 1940;8:212.

[36] Avrami M. Granulation, Phase Change, and Microstructure Kinetics of Phase Change. III. Journal of Chemical Physics 1941;9:177.

[37] Johnson W, Mehl R. Reaction kinetics in processes of nucleation and growth. Trans. AIME 1939;135.

[38] Kolmogorov A. A statistical theory for the recrystallization of metals. Akad. nauk SSSR, Izv., Ser. Matem 1937;1.

[39] Li JJ, Wang JC, Xu Q, Yang GC. Comparison of Johnson-Mehl-Avrami-Kologoromov (JMAK) kinetics with a phase field simulation for polycrystalline solidification. Acta Materialia 2007;55:825.

[40] Inoue T, Arimoto K. Development and implementation of CAE system hearts for heat treatment simulation based on metallo-thermo-mechanics. Journal of Materials Engineering and Performance 1997;6:51.

[41] Chen LQ. PHASE-FIELD MODELS FOR MICROSTRUCTURE EVOLUTION. Annual Review of Materials Research 2002;32:113.

[42] Dobrzanski L, Trzaska J. Application of neural networks for the prediction of continuous cooling transformation diagrams. Computational Materials Science 2004;30:251.

[43] Maazi N, Penelle R. Introduction of preferential Zener drag effect in Monte Carlo simulation of abnormal Goss grain growth in the Fe-3\%Si magnetic alloys. Materials Science and Engineering: A 2009;504:135.

[44] Leblond JB, Mottet G, Devaux JC. A theoretical and numerical approach to the plastic behaviour of steels during phase transformations: -I. Derivation of general relations. 1986;34:395. 


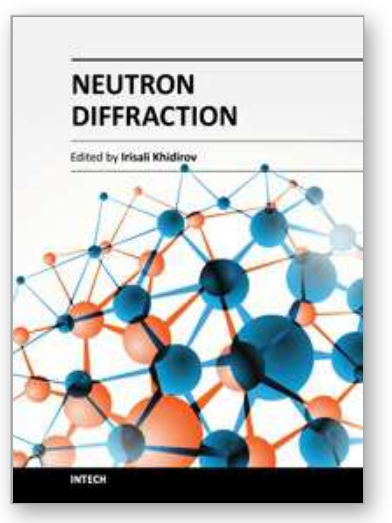

\author{
Neutron Diffraction \\ Edited by Prof. Irisali Khidirov
}

ISBN 978-953-51-0307-3

Hard cover, 286 pages

Publisher InTech

Published online 14, March, 2012

Published in print edition March, 2012

Now neutron diffraction is widely applied for the research of crystal, magnetic structure and internal stress of crystalline materials of various classes, including nanocrystalls. In the present book, we make practically short excursion to modern state of neutron diffraction researches of crystal materials of various classes. The book contains a helpful information on a modern state of neutron diffraction researches of crystals for the broad specialists interested in studying crystals and purposeful regulation of their service characteristics, since the crystal structure, basically, defines their physical and mechanical properties. Some chapters of the book have methodical character that can be useful to scientists, interested in possibilities of neutron diffraction. We hope, that results of last years presented in the book, can be a push to new ideas in studying of crystalline, magnetic structure and a macrostructure of usual crystal materials and nanocrystals. In turn, it can promote working out of new materials with new improved service characteristics and to origin of innovative ideas.

\title{
How to reference
}

In order to correctly reference this scholarly work, feel free to copy and paste the following:

Hui Dai (2012). Modelling Residual Stress and Phase Transformations in Steel Welds, Neutron Diffraction, Prof. Irisali Khidirov (Ed.), ISBN: 978-953-51-0307-3, InTech, Available from:

http://www.intechopen.com/books/neutron-diffraction/modelling-residual-stress-and-phase-transformations-insteel-welds

\section{INTECH}

open science | open minds

\author{
InTech Europe \\ University Campus STeP Ri \\ Slavka Krautzeka 83/A \\ 51000 Rijeka, Croatia \\ Phone: +385 (51) 770447 \\ Fax: +385 (51) 686166 \\ www.intechopen.com
}

\author{
InTech China \\ Unit 405, Office Block, Hotel Equatorial Shanghai \\ No.65, Yan An Road (West), Shanghai, 200040, China \\ 中国上海市延安西路65号上海国际贵都大饭店办公楼 405 单元 \\ Phone: +86-21-62489820 \\ Fax: $+86-21-62489821$
}


(C) 2012 The Author(s). Licensee IntechOpen. This is an open access article distributed under the terms of the Creative Commons Attribution 3.0 License, which permits unrestricted use, distribution, and reproduction in any medium, provided the original work is properly cited. 